This article can be cited before page numbers have been issued, to do this please use: M. L. Uhrig, B. Lantaño and A. Postigo, Org. Biomol. Chem., 2019, DOI: 10.1039/C9OB00405J.

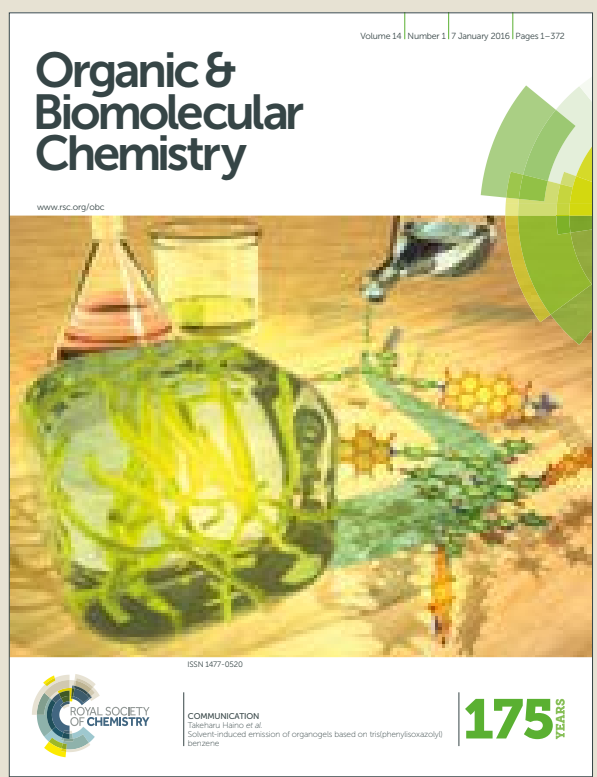

This is an Accepted Manuscript, which has been through the Royal Society of Chemistry peer review process and has been accepted for publication.

Accepted Manuscripts are published online shortly after acceptance, before technical editing, formatting and proof reading. Using this free service, authors can make their results available to the community, in citable form, before we publish the edited article. We will replace this Accepted Manuscript with the edited and formatted Advance Article as soon as it is available.

You can find more information about Accepted Manuscripts in the author guidelines.

Please note that technical editing may introduce minor changes to the text and/or graphics, which may alter content. The journal's standard Terms \& Conditions and the ethical guidelines, outlined in our author and reviewer resource centre, still apply. In no event shall the Royal Society of Chemistry be held responsible for any errors or omissions in this Accepted Manuscript or any consequences arising from the use of any information it contains. 


\section{SYNTHETIC STRATEGIES FOR FLUORINATION OF CARBOHYDRATES}

Received 00th January 20xx, Accepted 00th January 20xx

DOI: $10.1039 /$ x0xx00000x

www.rsc.org/

\author{
María Laura Uhrig, ${ }^{[a, b]}$ Beatriz Lantaño, ${ }^{[c]}$ and Al Postigo* ${ }^{[c]}$
}

This review article discusses different synthetic strategies for accomplishing regio- and stereoselective fluorinations of the sugar moiety, discussing the reaction mechanisms and some biological implications arising from such substitutions

\section{INTRODUCTION}

During the last decades, the investigations on the role of carbohydrates, mainly those linked to proteins and lipids, revealed their central participation in a wide variety of physiological processes.[1-4] Among them, fluorine-substituted carbohydrate derivatives have been intensively explored.[5] Deoxyfluoro carbohydrates (where one $\mathrm{OH}$ group has been replaced by F) have been used as probes of glycosidase mechanisms. [6] As a matter of fact, fluorine substitution has a direct influence on the rate of reaction in a manner that is dependent on its position on the carbohydrate with respect to the anomeric center, as expected for a reaction mechanism that bears carbenium ion character.[7]

On the other hand, one of the most prevalent means to modulate chemical properties of small molecules is by means of introducing fluorine, often considered an isostere of hydrogen.[8,9] However, it should be noted that fluorine's van der Waals radius $(1.47 \AA)$ is closer to oxygen $(1.52 \AA)$ than that of hydrogen (1.20 ̊).

The $\mathrm{C}-\mathrm{F}$ and $\mathrm{C}-\mathrm{OH}$ groups are also recognized as bioisosteric motifs although some important differences have to be taken into consideration.[10] One very important fact is that the $\mathrm{OH}$ group can act as both hydrogen donor and acceptor, whereas a F substituent can only act as hydrogen acceptor.[11] In this regard, ${ }^{1} \mathrm{H}-\mathrm{NMR}$ spectroscopy has become a powerful tool to detect intramolecular $\mathrm{O}-\mathrm{H} \cdots \mathrm{F} \quad \mathrm{H}$-bonds $[12,13]$ by scalar

[a] Prof. Dr. María Laura Uhrig

Universidad de Buenos Aires, Facultad de Ciencias Exactas y Naturales, Departamento de Química Orgánica, Pabellón 2, Ciudad Universitaria, C1428EG Buenos Aires, Argentina

[b]Consejo Nacional de Investigaciones Cientificas y Técnicas (CONICET)UBA. Centro de Investigación en Hidratos de Carbono (CIHIDECAR).

Buenos Aires, Argentina

[c] Dr. Beatriz Lantaño, Prof. Dr. Al Postigo*

Departmento de Química Orgánica, Facultad de Farmacia y Bioquímica, Universidad de Buenos Aires

Junin 954 CP1113-Buenos Aires, Argentina

E-mail:apostigo@ffyb.uba.ar couplings between $\mathrm{F}$ and $\mathrm{OH}\left({ }^{\mathrm{h} 1 \mathrm{~J}}(\mathrm{~F}, \mathrm{OH})\right)$ in nonpolar solvents.[14-17]

The intramolecular $\mathrm{H}$-bonding of fluorinated pyranosides has been the subject of several studies. For example, Gouverneur, Bernet and colleagues [18] studied the intramolecular $\mathrm{H}$-bonding of 1,3-diaxial fluoro- and hydroxysubstituents, including the influence of the nature and orientation of the vicinal O-substituents. Replacing $\mathrm{CHF}$ by $\mathrm{CF}_{2}$ serves to probe the diverse $\mathrm{H}$-accepting properties of both groups. ${ }^{19} \mathrm{~F}-\mathrm{NMR}$ experiments have and are currently being employed to elucidate carbohydrate-protein interactions when appropriately fluorine-substituted sugar mimetics/sugar analogues are used.[19-21] These latter experiments applied to the elucidation of carbohydrate-protein interactions have recently been reviewed [22-24] and will not be dealt with in this review article.

Although $\left[{ }^{18} \mathrm{~F}\right]$-fluorination strategies of carbohydrates will not be the subject of this review article, [18F]-glycosides are used as positron emission tomography (PET) agents, being 2[18F]-fluoro-2-deoxyglucose the standard radiotracer for PET neuroimagen and diagnostic tool.[25,26]

There already exist review articles on the synthesis and applications of fluorinated carbohydrates that have attested to their relevance in the fields of organic synthesis, biomedical applications, and function in biological systems.[27-30] However, the aim of the present work is to discuss the synthetic procedures and strategies used to incorporate the fluorine atom in the carbohydrate skeleton, with special emphasis on the new methodologies that have not been dealt with before in review articles.[27-29] When appropriate, discussions on the mechanisms of selected fluorination strategies will be undertaken. Fluorination strategies of carbasugars, polyhydroxylated pyrrolidines, glycoimidazoles, and iminosugars will not be treated in this review article, neither incorporation of perfluoroalkyl chains (i.e.: introduction of $\mathrm{C}_{n} \mathrm{~F}_{2 n+1}(\mathrm{n} \geq 1$ ) groups) onto carbohydrates, topics which deserve comprehensive treatments of their own. 


\section{1.- Fluorination Strategies of Carbohydrates}

Synthetic procedures to effect fluorination reactions on carbohydrates include nucleophilic and electrophilic fluorination sources, radical approaches, and the de novo (building block) strategy to generate fluorinated sugars from non-carbohydrate precursors.

Among nucleophilic sources for fluorination of carbohydrates, deoxyfluorination of hydroxyl groups using DAST 1 (diethylaminosulfur trifluoride) (Figure 1),[31,29] or its methyl and morpholino analogues, Deoxofluor 2 (bis(2methoxyethyl)aminosulfur trifluoride) [32], DFMBA $3(\mathrm{~N}, \mathrm{~N}-$ diethyl- $\alpha, \alpha$-difluoro- $m$-methylbenzylamine) [33], have been the most common fluorine sources. Reactions via nucleophilic substitution of activated hydroxyl groups with fluoride sources such as CsF [34], or (TMS) $\mathrm{CF}_{3}$ (trifluoromethyl)trimethylsilane), or the use of TASF 4 (Figure 1) (tris(dimethylamino)sulfur(trimethylsilyl)difluoride) can also be employed in fluorination of saccharides.[35] Hydrogen fluoride,[29,36] iodine-, bromine-, and chlorine-fluorides can also yield the fluoride anion for nucleophilic fluorination reactions of carbohydrates. Other methods include electrophilic addition of $F$ onto glycans through the employment of Selectfluor $5 \quad$ (1- chloromethyl-4-fluoro-1-,4diazoniabicyclo[2.2.2] octane bis(tetrafluoroborate) [37] or the triflate salt 6 , and radical type reactions, which have found renewed interest as fluorination methods of sugars.
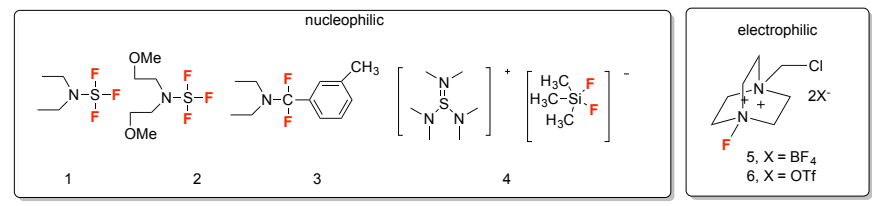

Figure 1. Structures of fluorinating reagents DAST (1) [29], Deoxofluor (2) [32], DFMBA (3) [33], TASF (4), and Selectfluor $(5,6)$

The introduction of fluorine in various positions of a carbohydrate scaffold can serve different purposes.[38] Taking into account that the regio- and the stereoselectivity of the different carbohydrate positions substituted with fluorine(s) have introduced remarkable changes in conformation stabilities and revealed profound differences in biological activity, a classification based on the regio- and stereoselectivity of fluorine-substituted carbohydrates will aid the researcher into searching for more comprehensive synthetic strategies towards the sought fluorinated targets. Consequently, this review article (unlike previously published [27a] where functional group transformations within the sugar moiety into fluorinated sites are described, or where reactions are subordinated to the different fluorinating reagents [29]), will be organized taking into consideration the synthetic routes for accomplishing stereoselective fluorinations at the different positions of the sugar moiety. Section 2 will deal with monofluorination synthetic strategies of carbohydrates while section 3 will focus on the introduction of multiple fluorine atoms into the sugar scaffold.

\section{2.-Synthesis of Monofluorinated Saccharides ticle Online DOI: 10.1039/C9OB00405]}

\section{1.-Synthesis of 1-fluoromonosaccharides}

Glycosyl fluorides [29] have amply been used in chemical $O$ glycosylation and $C$-glycosylation methods as glycosyl donors. Pyranosyl and furanosyl fluorides are effectively activated by fluorophilic reagents. A review article describing the diverse $O$ glycosylation and $C$-glycosylation methods with 1deoxyfluoromonosaccharides attests to the relevance of glycosyl fluorides.[39,29] Therefore, procedures that converge into the syntheses of 1-fluoro-carbohydrates have great relevance in glycosylation processes.

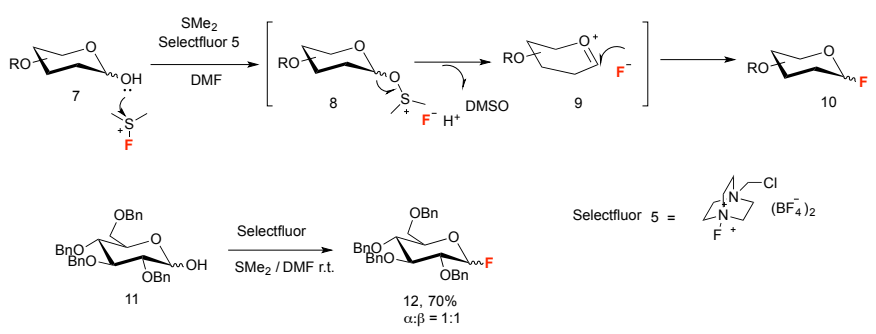

Scheme 1a. 1-OH monosaccharides 7 transformed to 1-F-derivatives 10 using 1(chloromethyl)-4-fluoro-1,4-diazoniabicyclo[2.2.2]octane ditetrafluoroborate $\mathbf{5}$

1-OH monosaccharides (such as 7, Scheme 1a) can be transformed to 1-F-derivatives $\mathbf{1 0}$ using Selectfluor 5, (Figure 1) and methyl sulfide.[40] The anomeric hydroxyl group reacts with the fluorosulfonium ion followed by the displacement of sulfoxide by fluoride (Scheme 1a).

When only the $\alpha$ - anomer is obtained, the reaction is presumed to be controlled by the anomeric effect and proceeds through an oxocarbenium intermediate, i.e.: through an $\mathrm{S}_{\mathrm{N}} 1$ mechanism. Only for the case of 2-azido-derivatives, an inversion of the configuration of the anomeric position was observed, albeit low yields of the 2-azido- $\alpha$-fluoroglycoside were obtained when the 2-azido- $\beta$-thioglycoside starting material was used. The hypothesis given by the authors [41] that the reaction proceeded through a $\mathrm{S}_{\mathrm{N}}$ 2-like mechanism can be supported by the absence of an oxocarbenium-stabilizing group in $\mathrm{C}-2$. In any case, the stereochemistry of the reaction with DAST probably depended on both electronic and steric factors in the vicinity of the anomeric carbon.

Glycosyl fluorides can be obtained from thioglycosides using $\mathrm{N}, \mathrm{N}$-diethylaminosulfur trifluoride (DAST) [41] in the presence of $\mathrm{N}$-bromo succinimide (NBS), Scheme $1 \mathrm{~b}$. One of the problems with this reaction is the formation of unstable glycosyl bromides that make purification difficult. Fluorination using DAST in the absence of NBS suggests that the Vilsmeier-type electrophilic sulfinium cation species formed from DAST would activate the thioglycoside by itself. It has been reported that fluorination promoted by DAST requires higher temperatures because the electrophilicity of the reactive species derived from DAST is rather low. 


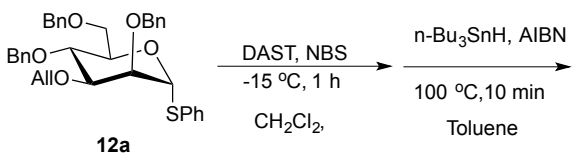

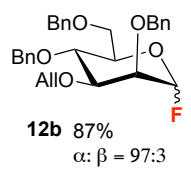

Scheme $1 b$. Reaction of O-allyl-protected phenylthio glycoside 12a with DAST and NBS

Kanie and co-workers [41] carried out a study to optimize the conditions of the method without using NBS. The phenylthioglycoside derived from galactose was protected with chloroacetyl groups in the $O-2$ - position and benzyl groups in $O$ $3,0-4$ and $O-6$ positions. The reaction was complete in 3.5 hours at $40^{\circ} \mathrm{C}$ using 2.0 equiv of DAST in 1,2-dichloroethane as solvent in an almost quantitative yield. These conditions can be applied by using 2-azido group and di-O-chloro acyl derivatives as substrates. It was shown that 2 -azido and di-O-chloroacyl protecting groups are compatible with these conditions.

Glycosylfluorides were also synthesized from (phenylthio)glycosides, by using $\mathrm{IF}_{5}-$ pyridine- $\mathrm{HF}$, an air- and moisture-stable fluorinating reagent, in $\mathrm{CH}_{2} \mathrm{Cl}_{2}$ at room temperature (Scheme 1c).

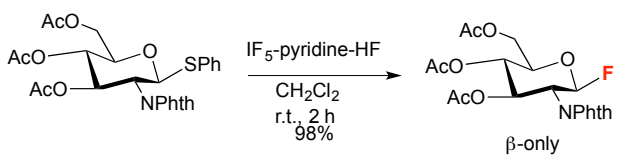

Scheme 1c. Synthesis of glycosylfluorides from (phenylthio)glycosides, by using $\mathrm{IF}_{5}-$ pyridine-HF

The reaction (Scheme 1c) required 2 equivalents of the reactant, and was completed in $2 \mathrm{~h}$. The reaction conditions were shown to be compatible with a variety of protecting groups: acetate, benzyl ether, TBS groups and acetonides. The yields of isolated products were high (65-98\%) and the typical anomeric $\alpha: \beta$ ratio, estimated by ${ }^{19} \mathrm{~F}$ NMR, was shown to be $\cong$ 1:2.[4]

$$
\text { Selectfluor }
$$

Scheme 2. Glycosylfluorides 16 synthesized from (phenylthio)glycosides $\mathbf{1 3}$
Selectfluor allows the syntheses of glycosyl fluorides 16 from thioglycosides 13, thus replacing thelDAST3Pégene [299]; this latter is used in the presence of an activator to carry out this transformation (Scheme 2).

Examples of such transformations are depicted in Scheme 2. Upon treatment of monosaccharide derivative 18 (Scheme 2) with Selectfluor, a nucleophilic anomeric substitution of thiophenyl by $\mathrm{F}$ takes places, affording products 19 (82\% combined yield) as a mixture of 1-fluorinated anomers $(\alpha / \beta=1: 1)$. In agreement with this finding, Selectfluor was useful as activator of thioglycosides in glycosylation reactions (product 21).

D-manno-heptulose fluorinated analogs can serve as potential agents of high specificity for in vivo, non-invasive imaging of pancreatic beta cells and inhibition of tumor growth. Waschke, Thiem, and colleagues [33b] have accomplished the synthesis of 1-deoxy-1-fluoro-D-manno-heptulose 24 starting from prepared exocyclic enol ether $\mathbf{2 2}$ in a two-step synthesis, according to Scheme 3.
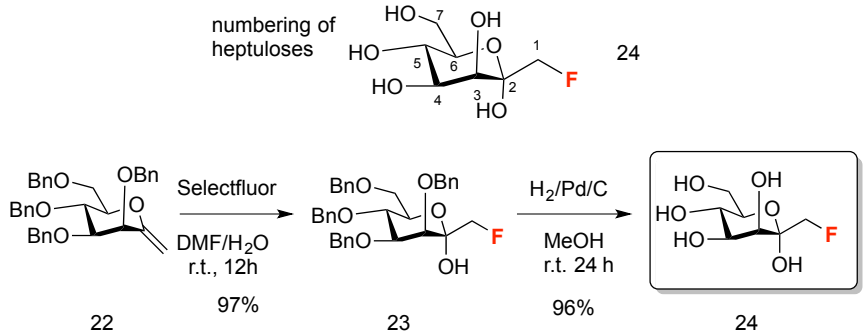

Scheme 3. Synthesis of 1-deoxy-1-fluoro-D-glycero- $\alpha$-D-lyxo-hept-2-ulopyranose $\mathbf{2 4}$

First 22 was fluorinated using Selectfluor affording 3,4,5,7tetra-O-benzyl-1-deoxy-1-fluoro- $\alpha$-D-glycerol-D-lyxo-hept-2ulopyranose $\mathbf{2 3}$ in $\mathbf{7 5 \%}$ yield (only the $\alpha$-anomer was formed). After hydrogenation, 1-deoxy-1-fluoro-D-glycero- $\alpha$-D-lyxohept-2-ulopyranose $\mathbf{2 4}$ was obtained in $\mathbf{7 3 \%}$ yield.

\section{2.- Synthesis of -2-fluoromonosaccharides. Reaction Mechanisms}

Early reported methods for the rapid synthesis of 2-deoxy2-fluorosugars utilize the displacement of trifluoromethylsulfonyloxy groups by reagents such as tris(dimethylamino)sulfur(trimethylsilyl)difluoride $\quad 4 \quad$ (TASF) under mild conditions.[35a,b] In most cases, the displacement of the trifluoromethylsulfonyl anion (triflate anion) occurs rapidly in refluxing DCM with inversion of configuration around the 2-position. Two such examples are illustrated in Scheme 4.

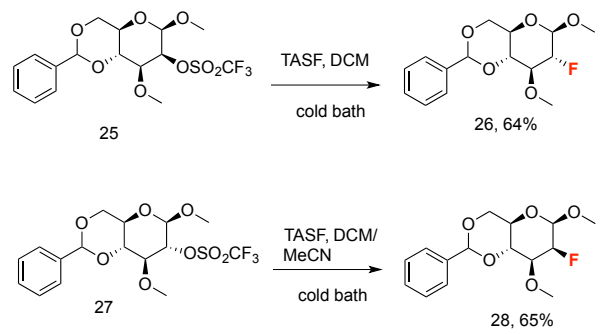

Scheme 4. Syntheses of 2-deoxy-2-fluoromonosaccharides with TASF 4 
The reaction of mannopyranoside 25 afforded methyl 4,6$O$-benzylidene-2-deoxy-2-fluoro-3-O-methyl- $\beta$-D-

glucopyranoside $\mathbf{2 6}$ in $64 \%$ yield, while glucopyrannoside $\mathbf{2 7}$, under similar conditions, afforded methyl 4,6-O-benzylidene-2deoxy-2-fluoro-3-O-methyl- $\beta$-D-mannopyranoside 28 in $65 \%$ yield (Scheme 4).[35b]

Other methods for preparing 2-deoxy-2-fluoro monosaccharides suffered from difficult or dangerous procedures and poor yields. The most rehearsed of these strategies involved the use of molecular fluorine or solid xenon difluoride upon reaction with glycals. Unfortunately, these methods necessitate harsh reaction conditions to hydrolyze the resulting 1,2-difluoro saccharides and often provide low yields. The use of DAST [29] also involves inversion of stereochemistry, which is not feasible to many synthetic applications.

One of the pioneering successful transformations of glycals into fluoride sugar derivatives was performed by Burkart and coworkers [40] in 1997. By treatment of glycals 29 and 31 with Selectfluor 6, the group succeeded in the preparation of 2deoxy-2-fluoro monosaccharides $\mathbf{3 0}$ and $\mathbf{3 2}$ under very mild conditions (Scheme 5). These reactions rely on the use of Selectfluor as electrophilic source of fluorine, which upon addition to the double bond of glycals generates highlystabilized oxonium ions which can easily undergo nucleophilic substitutions by water or alcohols. 2-Deoxy-2-fluoro glycosides were also prepared by adding an alcohol as nucleophile to the reaction medium (33, Scheme 5). The authors [40] reported that the stereoselectivity of the addition depended on the steric constrains of the starting glycal. They [40] used an excess of nucleophile in $\mathrm{MeCN}$ as solvent, obtaining the $\alpha$-glycoside as the major product.

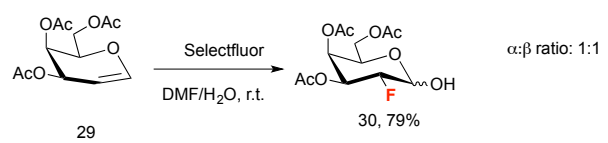
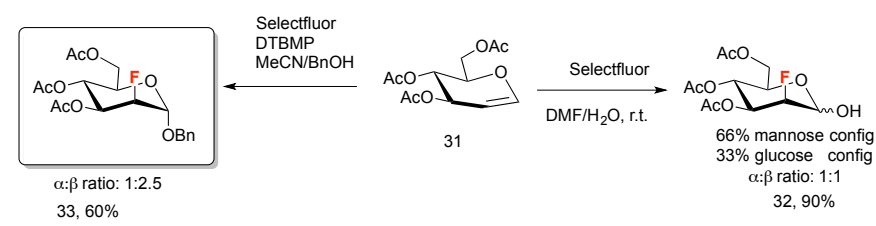

$33,60 \%$

$32,90 \%$

Scheme 5. Synthesis of 2-deoxy-2-fluorosugars by fluorination of glycals with Selectfluor

Vincent, Wong and colleagues [42] have more recently accomplished the fluorination / glycosylation of glycals employing Selectfluor as source of electrophilic $F$ atoms towards the practical synthesis of 2-deoxy-2-fluoro glycosides, including fluoro disaccharides, fluoroglycosyl phosphates, fluorinated natural product glycosides, and the synthesis of glycosyl sulfoxides from thioglycosides.

The authors [42] carried out a mechanistic study to understand the stereochemistry of the process and its optimization. In order to improve the performance and use of a wide range of nucleophiles they took into account the following parameters: solvent, reaction sequence and reagent counterion. The authors [42] noticed that the nucleophilic fluorination-addition rate was optimal when the solvent was

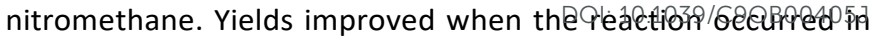
two steps: reaction of Selectfluor with the glycal, followed by addition of the nucleophile to the mixture. This consecutive sequence facilitated other possible nucleophiles to be employed independently of their reactivity with Selectfluor, thus increasing the functionality on the anomeric position. The best yields and fewest side products were obtained when triflate (i.e.: 6) was the counterion of Selectfluor.[42]

The reaction can be mechanistically separated into two stages. The first stage is the reaction of glycal $\mathbf{3 4}$ with Selectfluor to form the intermediate 35 which switches conformation to $\mathbf{3 5}^{\circ}$ (Scheme 6). The second stage is the reaction of this intermediate $\mathbf{3 5}$ (or conformer $\mathbf{3 5}^{\circ}$ ) with the nucleophile to render 38. The reaction was carried out with diacetylglucal 34 and Selectfluor triflate 6 because only the equatorial fluorinated product is obtained. The first stage was monitored by ${ }^{19} \mathrm{~F}$ and ${ }^{1} \mathrm{H}$ - NMR in $\mathrm{CD}_{3} \mathrm{NO}_{2}$ at different times (Scheme 6) in order to determine the mechanism of the attack by Selectfluor, the structure of the intermediate and the nature of the nucleophilic addition. At $15 \mathrm{~min}$ two compounds appeared as intermediates, 35 and 2-fluoro-diacetylglucal 36, which comes from the elimination of the reactive intermediate when found in the ${ }^{1} C_{4}$ conformation due to the trans-diaxial relationship of the leaving group and the $\mathrm{H}-2$. After $3 \mathrm{~h}$, a second intermediate, 37, began to form from $35^{\prime}$. Isolation and characterization of $\mathbf{3 7}$ showed it to be the epimerization product of $35^{\prime}$, in the ${ }^{1} \mathrm{C}_{4}$ conformation of the $\beta$-1-[TEDA- $\left.\mathrm{CH}_{2} \mathrm{Cl}\right]$-2-deoxy-2-fluoro intermediate. It could be assumed that an anomeric triflate intermediate is involved in this process, however it is considered unstable at room temperature. After $24 \mathrm{~h}$, the amount of $\mathbf{3 7}$ continued to increase at the expense of 35', (and 36 did not increase in concentration). In a separate experiment, conversion of $35^{\prime}$ to 37 reached $95 \%$ after $72 \mathrm{~h}$. When excess water was added, intermediate $\mathbf{3 5}$ was converted completely to the hydrolyzed form. Only a small amount of $\mathbf{3 7}$ was hydrolyzed after $24 \mathrm{~h}$ of being in contact with water at room temperature. Heating the mixture to $75^{\circ} \mathrm{C}$ for $30 \mathrm{~min}$ resulted in a complete hydrolysis of 37. These results indicate that the syn-adduct $35^{\prime}$ slowly epimerizes to the thermodynamically more stable form 37 . The difference in hydrolysis rates may be rationalyzed by the relative stability of each intermediate. Hence, the stereochemistry of the carbon-fluorine bond is determined prior to and independent of nucleophilic addition.[42]

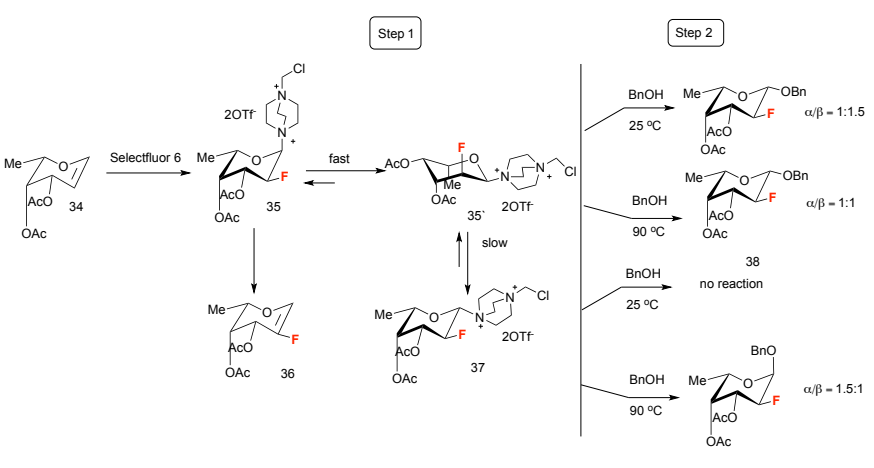

This journal is (C) The Royal Society of Chemistry 20xx 
To identify the mechanism of the nucleophilic attack, the reaction was carried out by varying the steric volume of the nucleophile. The anomeric $\alpha$ : $\beta$ ratio of the products with methanol, benzyl alcohol, cyclohexanol and tert-butyl alcohol was 40:60, 50:50, 45:55 and 70:30 respectively. These results suggested that an increase in steric volume in the nucleophile favored $\alpha$-selectivity. Therefore it was not a pure $\mathrm{S}_{\mathrm{N}} 2$ process. On the other hand, benzyl alcohol reacted separately with $\mathbf{3 5}$ (Scheme 6 ) and 37 at $90^{\circ} \mathrm{C}$, yielding an $\alpha: \beta$ anomeric mixtures of $1: 1.5$ and $3: 2$ as the product ratios. These results could be taken as evidence of a pure $S_{N} 1$ mechanism if both compounds had different patterns or might come from a competition between $\mathrm{S}_{\mathrm{N}} 1$ and $\mathrm{S}_{\mathrm{N}} 2$.[42]

The second experiment to elucidate the mechanism of the second step contemplates addition of benzyl alcohol to $35^{\prime}$ and 37 in a separate manner (Scheme 6, step 2). When benzyl alcohol is added to a sample of $3^{\circ}$ in $\mathrm{CD}_{3} \mathrm{NO}_{2}$ and heated to 100 ${ }^{\circ} \mathrm{C}$ for $15 \mathrm{~min}$, the product formed proved to be a 1:1 $\alpha / \beta$ anomeric mixture. The same protocol applied to 37 yielded a 3:2 $\alpha / \beta$ anomeric ratio. This suggests that both intermediates do not have the same transition state (if that were the case, the $\alpha / \beta$ ratio would have been the same from both epimers). These results can be rationalized by a pure $S_{N} 1$ mechanism, with the assumption that both intermediates $\left(3^{\prime}\right.$ and 37$)$ follow independent pathways, yielding dissimilar $\alpha / \beta$ ratios. An alternative explanation could interpreter the results by a competition between $\mathrm{S}_{\mathrm{N}} 1$ and $\mathrm{S}_{\mathrm{N}} 2$ mechanisms.

The reaction is carried out as follows: To a mixture of glycals and $4 \AA$ dry molecular sieves in dry nitromethane was added Selectfluor (1.1 equiv). After $6 \mathrm{~h}$ of stirring at room temperature under argon, a solution of the nucleophile in nitromethane is added quickly, and the solution is stirred at $100{ }^{\circ} \mathrm{C}$ for $1 \mathrm{~h}$. The mixture is poured onto dichloromethane, filtered through Celite, and concentrated. With the optimized reaction conditions in hand, several glycosides (Scheme 7) were synthesized in a single step in very good yields. Using benzoyl protecting groups in the glucal 39, the expected $\alpha$-anomeric selection takes place (i.e.: $\mathbf{4 1}$, Scheme 7).

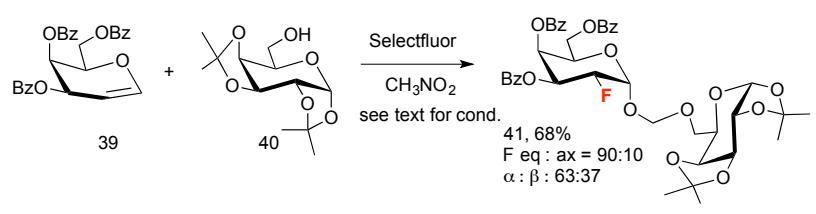

Scheme 7. Glycosylation using Selectfluor

Amines, phenols and amino acids can also serve as good nucleophiles, which must be utilized in the stepwise procedure. To demonstrate the usefulness of this technique, fluorinated analogues of two biologically active natural products (oleandrigenin derivative $\mathbf{4 3}$ from $\mathbf{4 2}$ and daunomycinone derivative $\mathbf{4 5}$ from $\mathbf{4 4}$ were synthesized (Scheme 8).[42]
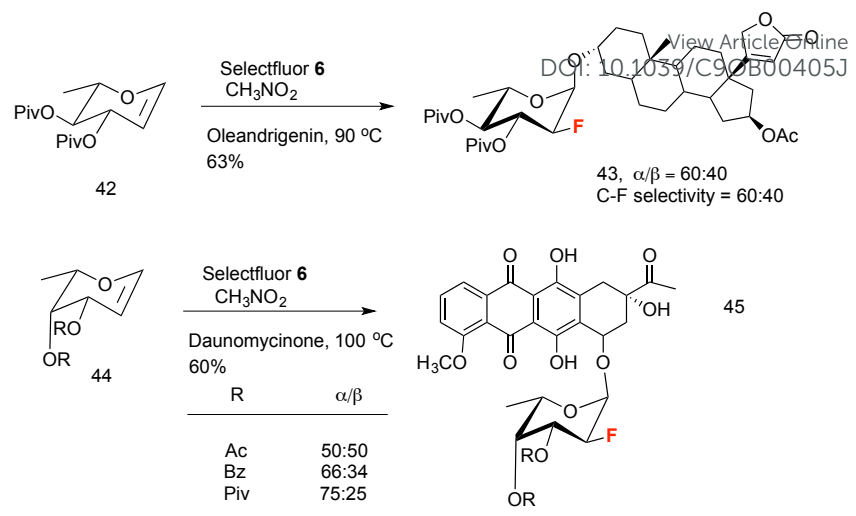

Scheme 8. Synthesis of oleandrigenin $\mathbf{4 3}$ and daunomycinone $\mathbf{4 5}$ derivatives

In the search for inhibitors of heptosyltransferases, enzymes involved in the biosynthesis of lipopolysaccharides present at the surface of gram-negative bacteria, the 2-fluorinated epimeric $\mathbf{4 6}$ and $\mathbf{4 7}$ were synthesized (Figure 2).[43,44]
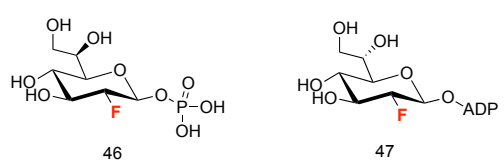

Figure 2. Structures of 2-fluorinated epimeric compounds $\mathbf{4 6}$ and $\mathbf{4 7}$

For the preparation of 46 (Scheme 9), the authors [44] started from D,D-heptose glycal $\mathbf{4 8}$ synthesized by standard methods and then studied its Selectfluor-mediated fluorination reaction in the presence of sodium dibenzylphosphate as nucleophile. A similar strategy was followed for the preparation of 47. [43]

The different product distributions between the stepwise and non-stepwise/one-pot methods could be found in the reaction mechanism. As mentioned before, Selectfluor addition occurs in a syn manner and that the intermediate adduct can anomerize after a ring flip. It is therefore acceptable to regard the first intermediate of the syn-addition of $\mathbf{4 8}$ as $\mathbf{4 9}$ (Scheme 9). As previously demonstrated on fucosides, the hindered DABCO ammonium can force the carbohydrate to flip to a ${ }^{1} C_{4}$ conformation, giving a new intermediate 50. Furthermore, an anomerization can also take place to form adduct $\mathbf{5 1}$, where the leaving group is now equatorial in a relaxed ${ }^{1} \mathrm{C}_{4}$ conformation. The stereochemical outcome of the global reaction is directly connected to the distribution of 49-51 (intermediates $\mathbf{4 9}$ and $\mathbf{5 0}$ are expected to favour nucleophilic substitutions from their $\beta$ face, while $\mathbf{5 1}$ should give an $\alpha$-selectivity). The distribution of intermediates 49-51 is dependent on all reaction parameters, including the temperature of the two steps (Selectfluor addition and nucleophilic substitution). As opposed to the stepwise procedure where the first step is always carried out at room temperature, the temperature of the whole process has been

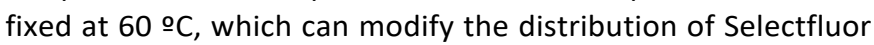
adducts but also the initial conformation of starting glycal $\mathbf{4 8}$. The $\alpha / \beta$ selectivity may also be affected by the nucleophilicity of the phosphate present from the beginning of the reaction in the non-stepwise procedure, and is therefore permitted to 
react with the intermediate adducts soon after their formation. Therefore, changing the reaction temperature and the addition sequence of this reaction would affect the stereoselectivity of the fluorophosphorylation.

The conditions to obtain the product having $\beta$-gluco configuration were optimized. On one hand, the protecting groups on the sugar showed a strong influence in the course of the addition: the best results were obtained using a TBSprotected precursor, although an $\alpha$-gluco product was obtained. The $\beta$-gluco product was also obtained from a pivaloylated precursor, albeit in lower yields. The results are consistent with an initial syn addition of Selectfluor, followed by a displacement of the DABCO ammonium anomeric residue by the phosphate anion. The DABCO-intermediate anion can flip to the ${ }^{1} C_{4}$ conformation, and an anomerization step is feasible, stabilized by reverse-anomeric effect. This could explain the product distribution obtained, which was also strongly dependent on the reaction conditions (Scheme 9).

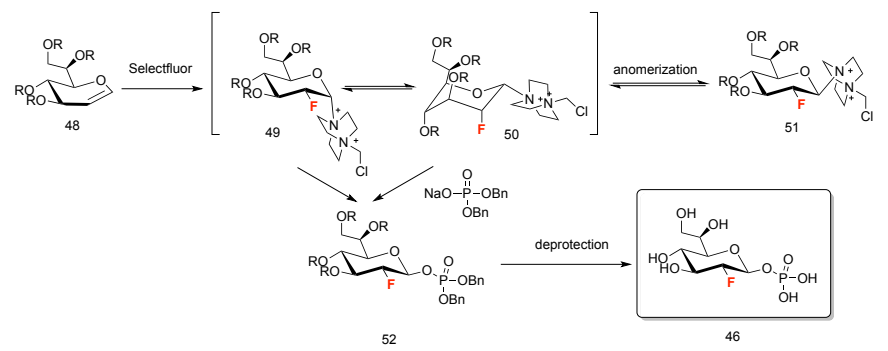

Scheme 9. Preparation of compound $\mathbf{4 6}$

Several glycosylation methods directed toward the synthesis of complex oligosaccharides have been developed. The main point of all these strategies is the formation of an intermediate oxonium ion, whose conformation is decisive to determine the configuration of the new formed anomeric center. Taking into account that organofluorine compounds adopt conformations that are stabilized by attractive electrostatic interactions and hyperconjugation, Gilmour and colleagues [45] carried out an investigation from the transient oxonium ions of 2-fluoropyranose derivatives. [45]

The effect of different protecting groups on the selectivity was also studied, (the inductive effects of protecting groups increase in the series benzyl < methyl < allyl and acetyl < pivaloyl). The 2-fluoro glucopyranose derivatives had the highest diastereoselectivity ( $\beta / \alpha=21: 1)$ unlike the deoxy derivative and the 2 -fluoro derivative of mannose $(\beta / \alpha \sim 3: 1)$. This tendency is observed also in the allyl series (F-glu> F-Mann> deoxy; $\beta$ / $\alpha$ 12: 1, 2.5: 1 2.1: 1 , respectively). The inversion of the C-2 configuration and the substitution with stronger inductive protecting groups such as acetyl and pivaloyl resulted in an exclusive diastereoselectivity towards the $\alpha$-anomer.

The ${ }^{3} \boldsymbol{H}_{\mathbf{4}}$ half-chair conformation (Scheme 11) that would explain these observed results in the transient oxonium ions, located the substituents in C-3 and C-4 in a pseudo-axial disposition improving the electrostatic stabilization. In addition, the position of the fluorine atom in C-2 is fundamental to direct stereoselectivity (structure $\mathbf{5 6}$, Scheme $\mathbf{1 1}$ ). As observed in the mannose series, the inversion of the C-2 confijguration

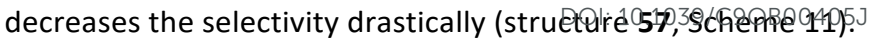

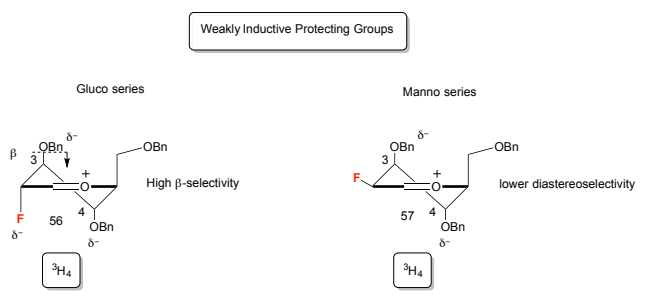

Scheme $11 .{ }^{3} \mathbf{H}_{4}$ half-chair conformations $\mathbf{5 6}$ and $\mathbf{5 7}$ in the transient oxonium ions

The high selectivity of $\alpha$ - anomer in the mannose series cannot be explained with the same model due to a change in the conformation where the substituents adopt a pseudoequatorial disposition and the ${ }^{4} \mathrm{H}_{3}$ conformation predominates (structure 59, Scheme 12).

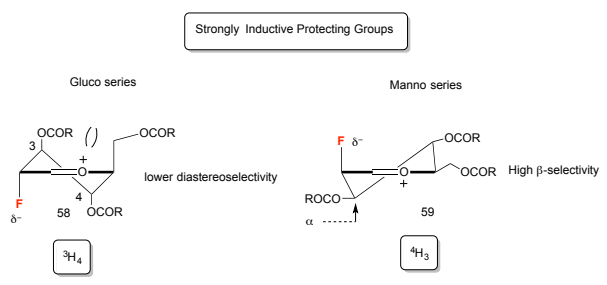

Scheme $12 .{ }^{4} \mathrm{H}_{3}$ conformation $\mathbf{5 9} \alpha$ anomer in the mannose series

This type of strategy was applied for the synthesis of SGLT2 inhibitors [46] for type II diabetes (Scheme 13). These compounds are $O$-glycosylated and $C$-glycosylated. They have in their structure a D-glucose unit with the anomeric bond of $\beta$ configuration. The introduction of a fluorine substituent in C-2 would not only influence the stereoselectivity of the glycosylation but would also allow to modulate parameters such as metabolic stability, $\mathrm{pK}_{\mathrm{a}}$ values of neighboring groups and lipophilicity (Scheme 13).

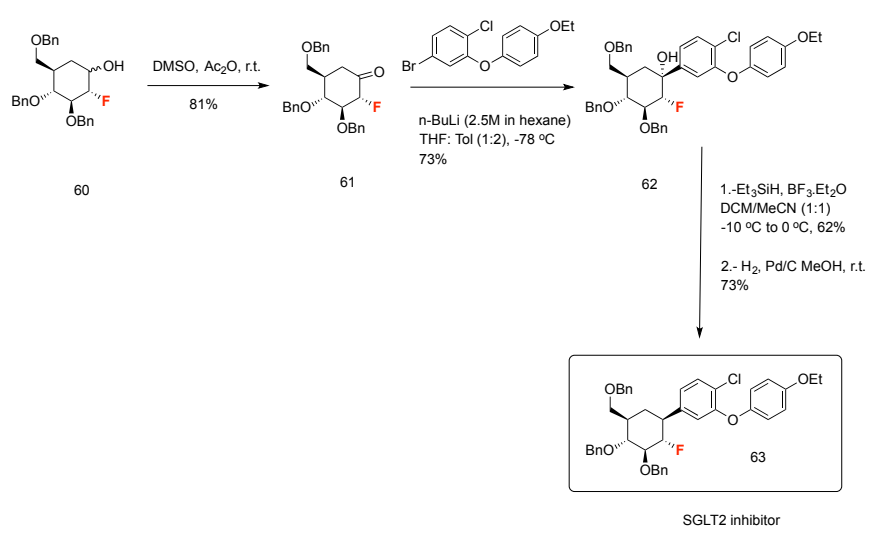

Scheme 13. Synthesis of SGLT2 inhibitors 63

In another study, Gilmour and co-workers [47] showed the influence of the substitution of the hydroxyl group in C-2 position for $F$ on the stereochemical course of the glycosylation 
reaction using D-glucose, D-mannose and D-galactose. The analysis of the mechanism shows that the high stereoselectivity of the $\beta$-anomer is due to the configuration of $\mathrm{C}-2$ and the nature of the protecting groups. The Felkin-Anh-Eisenstein induction model explains the 1,2- trans ratio in the majority of glycosides. The oxocarbenium ion model is in agreement with a significant $\mathrm{S}_{N} 1$ character for the fluoroglycosylation. It was also observed that the configuration at C-4 plays a decisive role in determining the $\alpha / \beta$ selectivity in the subsequent glycosylation. Through a series of temperature-dependent glycosylation experiments of perbenzylated 2-deoxy-2-fluoroD-glucose and 2-deoxy-2-fluoro-D-galactose (64-67, Scheme 14) using $i$-PrOH as a model glycosyl acceptor (Scheme 14), the authors extrapolated the differences in the enthalpic $\left(\Delta \Delta H \beta \alpha^{\ddagger}\right)$ and entropic $\left(\Delta \Delta S \beta \alpha{ }^{\ddagger}\right)$ contributions that allowed to discriminate so similar systems. The deoxyfluorination in C-2 presented a good stabilization of the $\beta$-transition state in terms of enthalpy. These data coincided with the assumption that orbital control by a Felkin-Anh-Eisenstein model (Figure 3a) was of central importance in the creation of the 1,2-trans (i.e., $\beta$ ) glycosidic linkage.
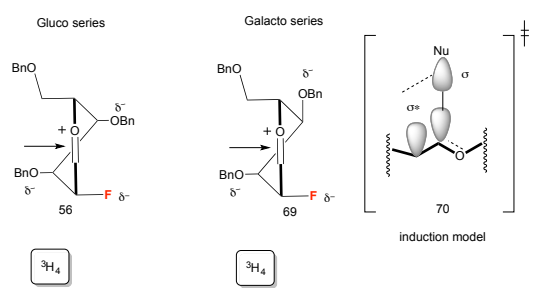

Figure 3a. Tentative transition states implicating orbital control ( $\left.\mathrm{C}-\mathrm{F}^{*}\right)$ to account for $\beta$-selectivity in chemical glycosylation

In order to illustrate the stereoselection in the Gluco and Manno series of a 2-F substituted carbohydrate scaffold with weakly inductive (OBn) and strongly inductive (OCOR) protecting groups, Figure $3 \mathrm{~b}$ is presented.
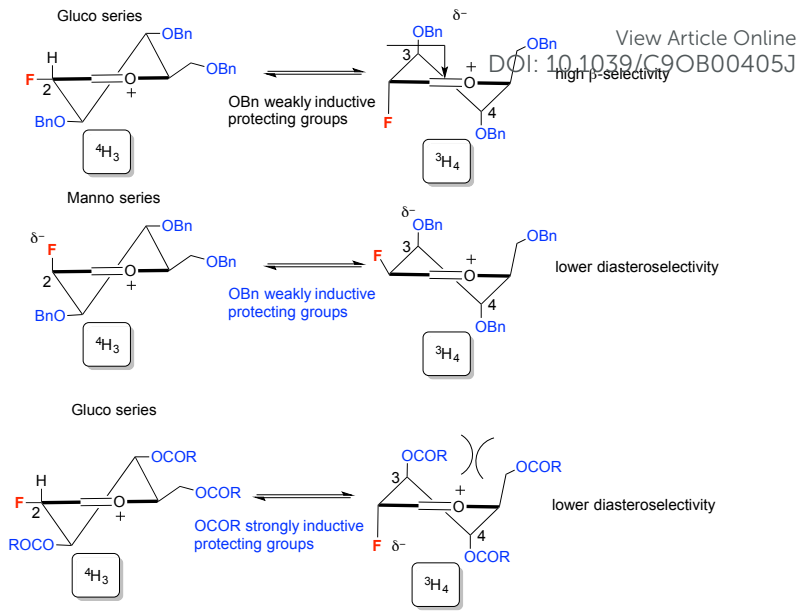

Manno series

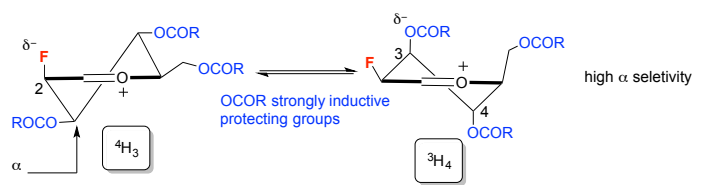

Figure 3b. Effects of weakly inductive and strongly inductive effects of 2-F-substituted Manno and Gluco series on the stereoselection of the glycosylylation reaction

In this Figure $3 \mathrm{~b}$ the strongly inductive protecting group OCOR induces a high $\alpha$-selectivity in glycosylation reactions in the Manno series, while the same protecting group in the Gluco series yields a lower diastereoselectivity in glycosylation reactions. Weakly inductive protecting groups such as $\mathrm{OBn}$ induce a high $\beta$-selectivity in the Gluco series while a lower diastereoselectivity in the Manno series for glycosylation reactions of 2-fluorine-substituted carbohydrates.

In conclusion, this study showed that substitution of fluorine atom at the $\mathrm{C}-2$ position of a perbenzylated pyranose scaffold increases $\beta$-stereoselection in a model glycosylation reaction.

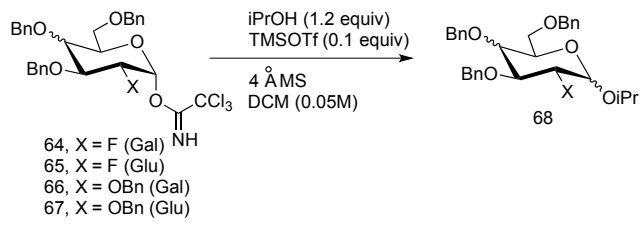

Scheme 14. Glycosylation experiments of perbenzylated 2-deoxy-2-fluoro-D-glucose $\mathbf{5 6}$ and 2-deoxy-2-fluoro-D-galactose 69 using $i$-PrOH as a model glycosyl acceptor

\section{3.- Synthesis of 3-fluoro monosaccharides [48]}

Preliminary fluorinations studies (deoxyfluorination) of the 3position of monosaccharides involve the use of tris(dimethylamino)sulfur(trimethylsilyl)difluoride 4 (TASF) from the respective triflate derivatives, as shown for the 2deoxyfluorination reactions (vide supra, Scheme 4).[35b]

Hara and colleagues [49] had informed the synthesis of methyl 3-deoxy-3-fluoro- $\beta$-D-xylopyranoside $\mathbf{7 2}$ in $70 \%$ yield (starting from 71) with tetrabutyl ammonium bifluoride and potassium hydrogen fluoride (TBABF / $\mathrm{KHF}_{2}$ ) through microwave irradiation at $150{ }^{\circ} \mathrm{C}$ in 30 minutes, according to Scheme 15 . 


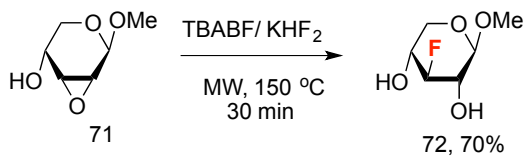

Scheme 15. Fluorination of epoxide $\mathbf{7 1}$ at the 3-position

$\mathrm{Hu}$ and co-workers [50] described an application of TBAF / $\mathrm{KHF}_{2}$ as nucleophilic fluorinating reagent using epoxide monosaccharides as starting materials. The authors [50] attempted D-arabinose epoxide $\mathbf{7 3}$ with the mixture TBAF / $\mathrm{KHF}_{2}$ at $120^{\circ} \mathrm{C}$ and obtained a single regioisomer 74 in $84 \%$ yield (Scheme 16). Treatment of 75 (Scheme 16) with TBAF/KHF 2 at $130{ }^{\circ} \mathrm{C}$ rendered product 76 in $84 \%$ yield. This compound corresponded to the trans-diaxial opening of the oxirane ring, as expected considering the Fürst-Plattner rule. In fact, ring opening of epoxide at C-3 is favored over C-2 attack which would produce a twist boat transition state (Figure 4).[50]

On the other hand, when the stereoisomeric epoxide 77 is subjected to the above- mentioned reaction at $130^{\circ} \mathrm{C}$, a mixture of 78 and 79 is obtained in combined $85 \%$ yield.

The major product $\mathbf{7 8}$ corresponds to the expected transdiaxial opening of the epoxide, whereas 79 corresponds to the trans-diequatorial opening of the oxirane ring, probably as the result of both steric and electronic factors, considering the presence of the benzylidene group in the $\beta$-face of the ring and the $\alpha$-disposition of the anomeric substituent. This result is in accordance with previous observations on the ring-opening reactions of epoxide sugars.[51]
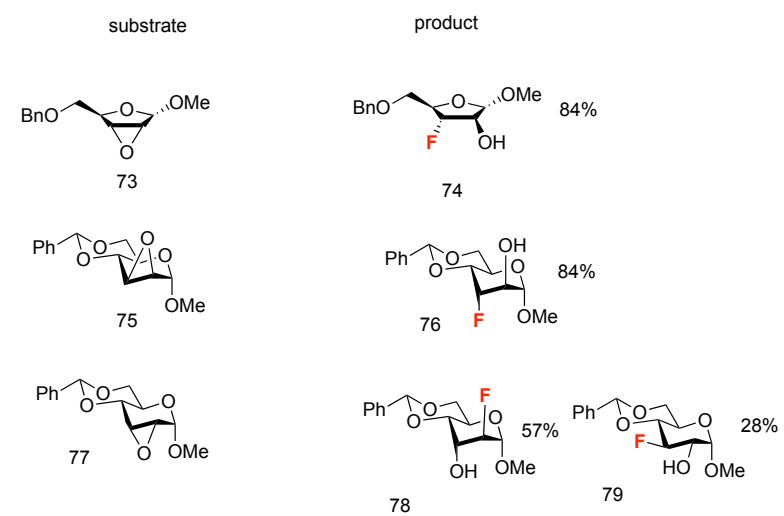

Scheme 16. Trans-diequatorial ring opening of epoxides with TBAF / $\mathrm{KHF}_{2}$

Ring opening of epoxide at C3 is favored over C2 attack which would produce a twist boat transition state (83, Figure 4).[50]

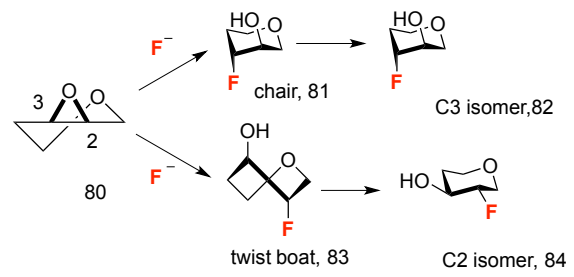

Karban et al. [52] synthesized a series of $3_{\text {Artiend }} \mathrm{g}_{\mathrm{nl}} \mathbf{4}_{\mathrm{e}}$ deoxyfluorinated analogues of D-galaetosamingerand40DI glucosamine, through the stereoselective introduction of an azide group as a masked amine group in C-2 and a fluorine substituent in carbon 3 by nucleophilic displacement. The formation of the 1,6-anhydro bridge reduces the number of protecting groups and the rigidity of the bicycles increases the regio- and stereoselectivity for the introduction of substituents in C-2, C-3 and C-4 positions. In Scheme 17, synthetic pathways to obtain the monofluoro analogs of 2-azido-3-deoxy-3-fluoro1,6-anhydrohexopyranoses 85 are presented.

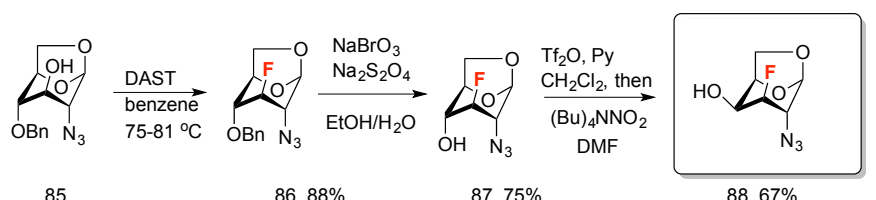

Scheme 17. Synthetic pathways are presented to obtain the monofluoro analogs of 2azido-3-deoxy-1,6-anhydrohexopyranoses 85

Compound $\mathbf{8 5}$ was treated with DAST to afford $\mathbf{8 6}$ in $\mathbf{8 8 \%}$ yield, which upon deprotection gave compound 87 in $75 \%$ yield. Compound $\mathbf{8 7}$ was transformed into compound $\mathbf{8 8}$ (with triflic anhydride and $(\mathrm{Bu})_{4} \mathrm{NNO}_{2}$ ) in $67 \%$ yield.

Wasch, Thiem and colleagues [33] have accomplished the synthesis of 3-deoxy-3-fluoro-D-manno-heptulose $\mathbf{8 9}$, starting from glycal 90 (Scheme 18). 3,4,6-tri-O-benzyl-D-glucal 90 was reacted with Selectfluor, affording 91 and 92 as a mixture of $\alpha$ and $\beta$-anomers in $77 \%$ overall yield (33\% yield of 3,4,6-tri- $O$ benzyl-2-deoxy-2-fluoro- $\alpha$-D-mannopyranose 91 , and $44 \%$ yield of 3,4,6-tri-O-benzyl-2-deoxy-2-fluoro-D-glucopyranose 92). Compound 91 was subjected to the synthetic route below, which upon treatment with acetic anhydride in DMSO afforded 3,4,6-tri-O-benzyl-2-deoxy-2-fluoro-D-manno-1,5-lactone 93 in $99 \%$ yield. This lactone was further subjected to methylenation with Petasis reagent (a cyclopentadienyl titanium methylene complex [53]) to afford 4,5,7-tri-O-benzyl-2,6-anhydro-1,3dideoxy-3-fluoro-D-mannohept-1-enitol 94 in $75 \%$ yield. Compound 94 was transformed to compound 95 through a Sharpless dihydroxylation in $97 \%$ yield. Lastly, hydrogenolysis of 95 afforded 3-deoxy-3-fluoro-D-glycero- $\alpha$-D-lyxo-hept-2ulopyranose 89 in $96 \%$ yield (Scheme 18).

Figure 4. Ring opening of epoxide $\mathbf{8 0}$ 

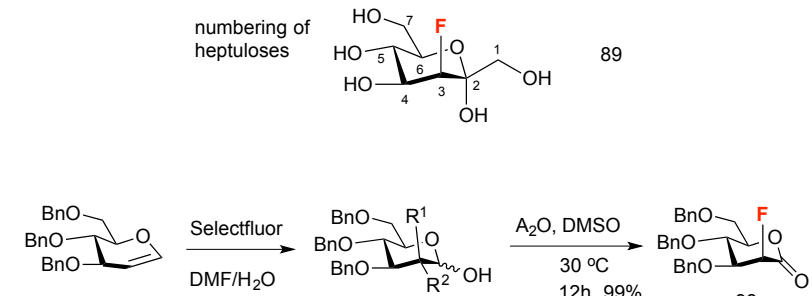

90 $12 \mathrm{~h}, 99 \%$ $91, R^{1}=F ; R^{2}=H(33 \%)$ $92, R^{1}=H, R^{2}=F(44 \%)$

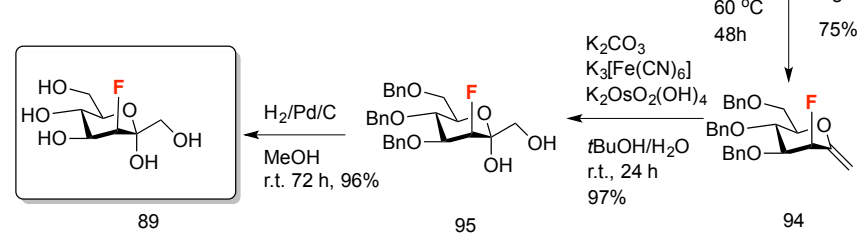

Scheme 18 . Synthesis of 3-deoxy-3-fluoro- $D$-glycero- $\alpha$-D-lyxo-hept-2-ulopyranose 89

\section{4.-Synthesis of -4-fluoro monosaccharides}

Preliminary fluorinations studies (deoxyfluorination) of the 4position of monosaccharides involve the use of tris(dimethylamino)sulfur(trimethylsilyl)difluoride (TASF) from the respective triflate derivatives, as shown for the 2-deoxyand 3-deoxy-fluorination reactions (vide supra, Scheme 4).[35b] Gouverneur and coworkers [10] have come up with a synthetic protocol to obtain 4-deoxy-4-fluoro- $\alpha$ - D -talopyranoside 97 as a starting material to prepare 4-deoxy-4-fluoro- $\alpha-D$ idopyranoside 102. These compounds are useful candidates to investigate intramolecular $\mathrm{H}$-bonds and allow to study possible changes arising from different configurations at C-3.

The proposed syntheses for compounds 97 (starting from 96) and 102 (starting from 101) are depicted in Scheme 19.

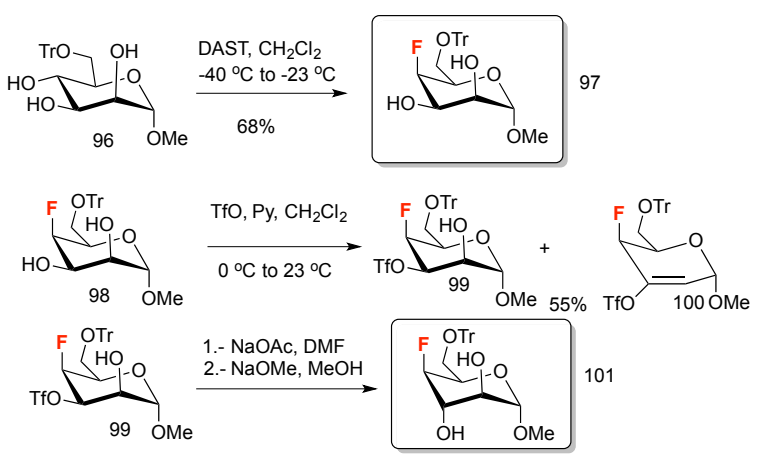

Scheme 19. Syntheses of compounds 97 and 101

The accessible 4-deoxy-4-fluoro- $\alpha$-D-talopyranoside 97 was transformed in three steps and $25 \%$ overall yield to the 4-deoxy4-fluoro- $\alpha$-D-idopyranoside $\mathbf{1 0 1}$ by inversion of the configuration at C-3.

Recent publications on the build-up of fluorinated disaccharides and trisaccharides for glycoconjugate vaccines, through glycosylation strategy attest to the relevance of the standard fluorination methodology with DAST.[19,29] These glycoconjugate vaccines contain 4-deoxy-4-fluoro ticlesugar $_{\text {sug }}$ moieties. DOI: $10.1039 / C 90 B 00405 \mathrm{~J}$

Recently Schalli and Stütz [54] have reported a simple method for obtaining hydroxymethyl-branched carbohydrates with a fluorine substituent. Examples of the syntheses of some sugars fluorinated at the 4-position (107) are depicted in Scheme 20.
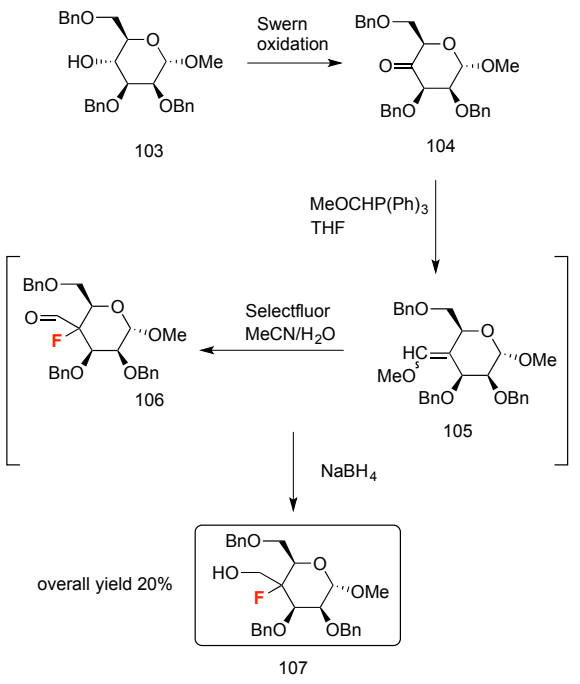

Scheme 20. Syntheses of hydroxymethyl-branched carbohydrates with a fluorine substituent

a-D-glucopyranoside 103 (obtained from commercial unprotected precursor 102, not shown) was oxidized to 104 and transformed to unstable 105, which underwent in situ fluorination by Selectfluor to afford 106, which upon reduction by $\mathrm{NaBH}_{4}$ gave product 107 in $20 \%$ yield (Scheme 20). [54]

Karban and colleagues [52] synthesized a series of 4deoxifluorinated analogues of D-galactosamine and Dglucosamine, through the stereoselective introduction of an azide group as a masked amine group in C-2 (108, Scheme 21$)$ and fluorine in carbon 4 by nucleophilic displacement (compound 109). The presence of the 1,6-anhydro bridge once again (vide infra) resulted beneficial for the regio- and stereoselective introduction of the substituents at C-2, C-3 and C-4 positions. In Scheme 21, a synthetic pathway is presented to obtain the mono- fluorinated analogues (i.e.: 109) of 2-azido4-deoxy-1,6-anhydrohexopyraoses 108.

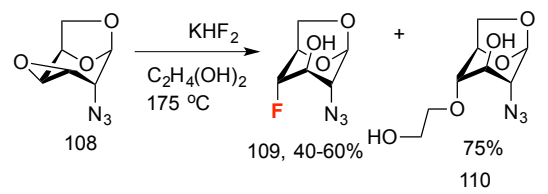

Scheme 21. Synthetic pathway to obtain the mono- fluoro analogs 109 of 2-azido-4deoxy-1,6-anhydrohexopyranoses 108

Subotkowski and colleagues [32] have accomplished the synthesis of 4-deoxy-4-fluoro epimer $\mathbf{1 1 4}$ in three steps commencing from the tetrabenzoylation of D-glucose $\mathbf{1 1 1}$ to 
afford 112, followed by formation of triflate 113 and fluorine substitution with tetrabutylammonium fluoride [55] (Scheme 22).

$$
{ }_{112,30 \%}
$$

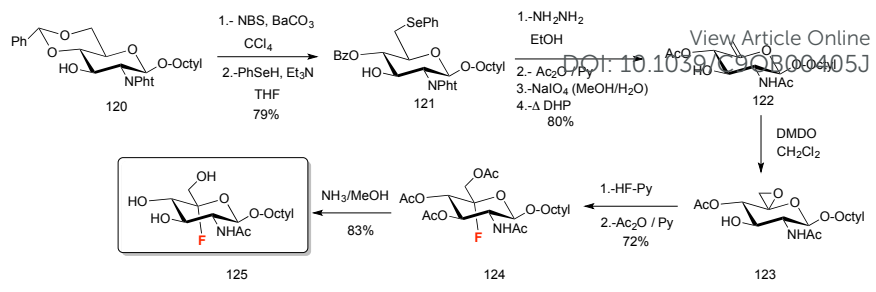

Scheme 24. Overall synthetic pathway for $\mathbf{1 2 5}$

The authors [56] next studied the synthesis of glycosyl phosphates having the 5-fluoro substituent, but by an alternative methodology, as the introduction of the anomeric phosphate group required a free anomeric position. This latter was achieved before the incorporation of the fluorine atom. The authors [56] had to overcome several issues, such as the presence of the NHAc group which presented additional challenges. They used a $\mathrm{N}$-trichloroacetate protecting group. Moreover, both $p$-methoxyphenyl and $t$-butyldimethylsilyl groups were studied as anomeric substituents in the following sequences (Scheme 25).

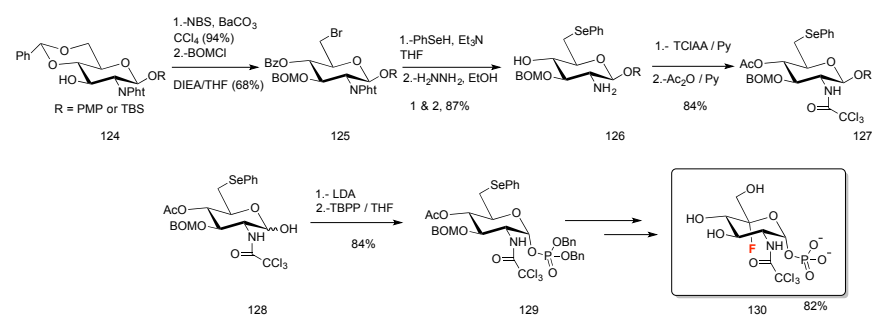

Scheme 25. Synthetic sequence for compound $\mathbf{1 3 0}$

The introduction of the phosphate group in C-1 was achieved through the corresponding free anomeric derivative by treatment with LDA and benzylpyrophosphate. The sequence was completed by selenoxide elimination by oxidation with $\mathrm{NaIO}_{4}$, then epoxidation and ring opening by fluoride, and deprotection, which led to the 5-fluoro glycosylphosphate target compound.

This derivative was tested in the reaction of the UDP-GIcNAC 4-epimerase, which transforms UDP-GIcNAc in UDP-GalNAc. The results showed that the electron withdrawing group at $\mathrm{C}-5$ position efficiently inhibits the epimerization, confirming the hypothesis that the adjacent fluorine would reduce the nucleophilicity of the hydroxyl groups at C-4 and C-6.

An alternative methodology [56] was proposed which involved the ring-opening of a 5,6-epoxide 123 ring by a fluoride, starting from an octyl- $N$-acetylglucosamine glycoside. Remarkably, the epoxidation step of the 5,6-alkene 122 proceeded in a diastereoselective manner. The overall yield of the following 10 -step sequence was $34 \%$ (Scheme 24).

\section{6.- Synthesis of 6-fluoromonosaccharides}

6-fluoro-5,6-anhydrocarbohydrates have been investigated as inactivators of $(S)$-adenosyl-L-homocysteine hydrolase.

Hara and colleagues [49] have studied the fluorination of epoxides leading to 6-fluoro-furanoses employing $\mathrm{Et}_{3} \mathrm{~N}-3 \mathrm{HF}$ mixtures by microwave irradiation, resulting in a considerable shortening of reaction times and improvement in yields, according to Scheme 26. 

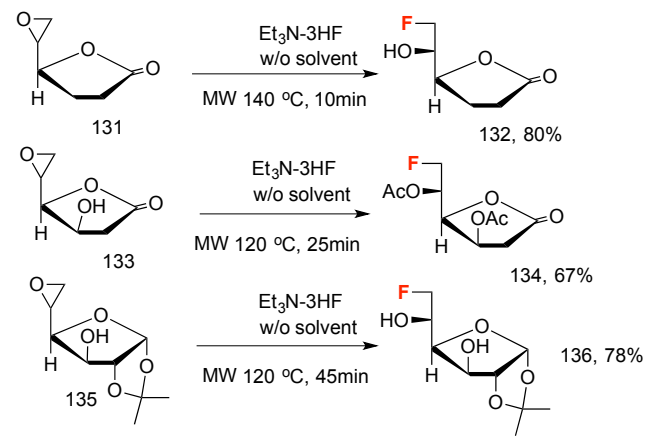

Scheme 26. Syntheses of 6-fluorocarbohydrates 132, 134, 136

The reaction of epoxide 131 (Scheme 26) gave 6-fluoroderivative 132 in $80 \%$ yield. Epoxide 133 afforded 6-fluoroderivative 134 in 67\% yield, while epoxide 135 gave product 136 in $78 \%$ yield. [49]

\section{7.-Synthesis of 7-fluoro-D-manno-heptulose}

Waschke, Thiem and colleagues [33] have accomplished the synthesis of 7-deoxy-7-fluoro- $D$-manno-heptulose 137 through a 10-step reaction-sequence. The target molecule could not be synthesized by standard fluorinated techniques and reagents such as Deoxofluor or Selectfluor, as these reagents led to cyclic anhydrides when attempts were made at replacing the $\mathrm{OH}$ group at 7 - position with the fluorine substituent. The reaction path depicted in Scheme 27 afforded the target compound (i.e.: 7-deoxy-7-fluoro-D-manno-heptulose 137).

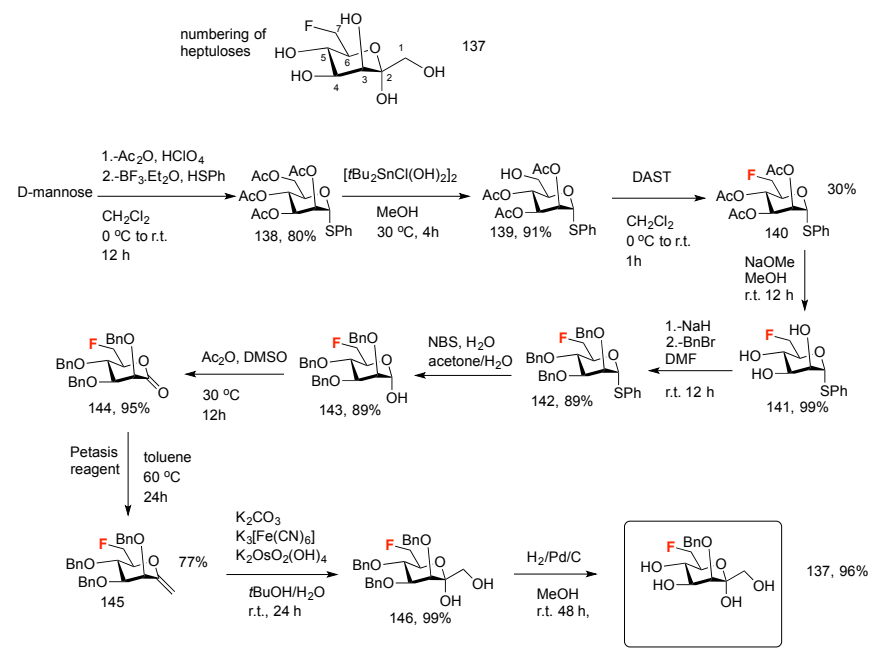

Scheme 27. Synthesis of 7-deoxy-7-fluoro-D-manno-heptulose 104

To start with, mannose (Scheme 27) was subjected to acetylation and ulterior thiophenylation to afford 138 in $80 \%$ yield. Regioselective cleavage of the primary acetyl group was accomplished with the organotin catalyst $\left[t \mathrm{Bu}_{2} \mathrm{SnCl}(\mathrm{OH})_{2}\right]_{2}$, obtaining 139 in $91 \%$ yield from 138. Fluorination of 139 with DAST afforded 140 in $30 \%$ yield. Benzylation and desulfuration afforded 143 in 89\% yield. Oxidation (with Petasis reagent [53]) of $\mathbf{1 4 3}$ afforded $\mathbf{1 4 4}$ in 95\% yield. Methylenation and dihydroxylation (Sharpless dihydroxylation) afforded dict $146_{\text {nlipg }}$

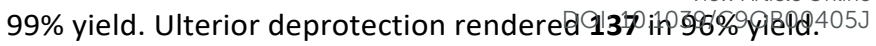

\section{3.-Synthesis of polyfluorinated saccharides}

\section{1.- Synthesis of dideoxy-difluorinated monosaccharides}

Established methods for the introduction of two fluorine atoms on a single carbon of a sugar scaffold consist of the transformation of the carbonyl moiety of the sugar into a $\mathrm{CF}_{2}$ by means of Deoxofluor 4 (Figure 1). These methods have been reviewed in 2010 by Guo and colleagues.[27a]

Nucleophilic ring opening reactions of carbohydrate-derived epoxides with fluorides have been shown to be a strategy for achieving fluorinated carbohydrates. Among the nucleophiles regularly employed are $\mathrm{KHF}_{2}$ [60] (Scheme 16), $\mathrm{Et}_{3} \mathrm{~N} .3 \mathrm{HF}$ [61,62], tetrabutylammonium bifluoride (TBABF / $\mathrm{KHF}_{2}$ ) [63], or a combination of tetrabutylammonium fluoride [55] and $\mathrm{KHF}_{2}$ (TBAF / $\mathrm{KHF}_{2}$ ) (vide supra, Scheme 16).[50]

Linclau and collaborators [64] have more recently accomplished the syntheses of mono- and difluorinated 2,3dideoxy-D-glucopyranoses employing epoxides, as shown in Scheme 28 below.

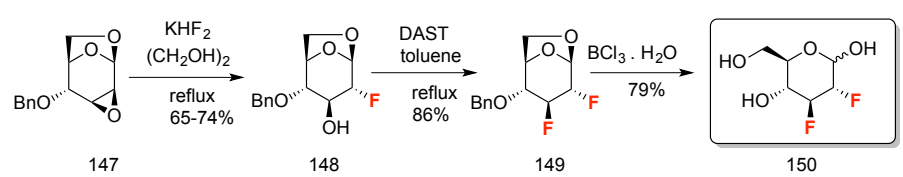

Scheme 28. Synthesis of difluorinated 2,3-dideoxy-D-glucopyranose $\mathbf{1 5 0}$

Regioselective ring opening of epoxide 2,3-anhydro-4-Obenzyl- $\beta$ - D-mannopyranose 147 by $\mathrm{KHF}_{2}$ in glycol as solvent afforded 148 in good yield (Scheme 28). DAST-mediated deoxofluorination of the $3-\mathrm{OH}$ of 148 , yielded the difluoride 149 in excellent yield (86\%). Benzyl deprotection and anomeric hydrolysis was attained in one pot by treatment of 149 with $\mathrm{BCl} 3$ followed by quenching with water, leading to pure $\mathbf{1 5 0}$ in $\mathbf{7 9 \%}$ yield.[64]

Karban and colleagues [52] synthesized a series of dideoxydifluorinated analogues of D-galactosamine and Dglucosamine, through the stereoselective introduction of an azide group (vide supra). In Scheme 29, synthetic pathways to obtain difluoro analogs of 2-azido-2-deoxy-1,6anhydrohexopyraoses 161 which is formed in $46 \%$ yield, and 162 (formed in $12 \%$ yield) are presented.

The reactions carried out with DAST [52] enable retention of the configuration, due to an assistance of the trans-diaxialdisposed polar groups at C-2 and C-4 (with respect to $\mathrm{C} 3-\mathrm{OH}$ ) polar groups at $\mathrm{C}-2$ or $\mathrm{C}-4$ positions, or by an internal fluorine attack as in $S_{N}$ i substitution. The compounds that possess an axial group on C-4 participate through an oxiranium intermediate. The rearranged difluoride comes from an anchimeric assistance of the azido group in C-2 position. The difluorinated products come from the same intermediary. Compound 165 (Scheme 29) can be formed from an internal 
attack of fluorine by a concerted mechanism or by contact ion pair (Scheme 29).[52]

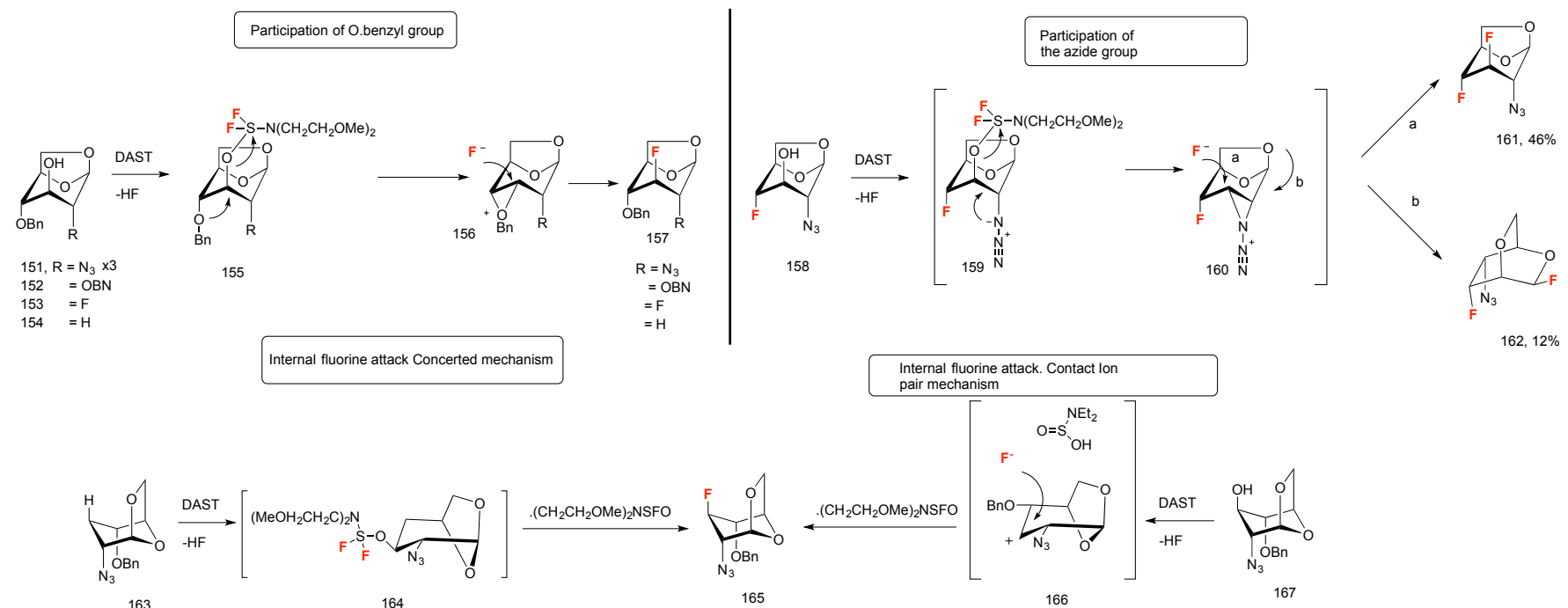

Scheme 29. Participation of the $O$-benzyl and azido groups to obtain 3,4-dideoxyfluorinated D-galactosamine and D-glucosamine derivatives 161 and 162

Fluorination of compound 158 with DAST (Scheme 29) can produce either products $\mathbf{1 6 1}$ and $\mathbf{1 6 2}$ (pathways a \& b, Scheme 29), albeit in very different yields. In pathway a, F anion attacks the 3-position of intermediate $\mathbf{1 6 0}$ opening the diazenylaziridine ring, while in path $b$ rearrangement of the sugar scaffold takes place, demonstrating the participation of the azide group in the regioselectivity of the fluorination reaction.[52]

\section{2.-Synthesis of trideoxy-trifluorinated saccharides [65]}

Erythrocytes have the ability to transport D-glucose through their cell membranes. These carriers can also recognize and transport the D-glucose analogues and thus can be used as a measure for such compounds to mimic glucose. Selectively fluorinated sugars, in particular, have been employed in transmembrane studies of erythrocytes by scanning the intracellular and extracellular levels of sugars using ${ }^{19} \mathrm{~F}-\mathrm{NMR}$.

O'Hagan and coworkers [66] carried out a study to synthesize hexoses (through a de novo approach) derived from D-glucose and D-altrose, where the secondary hydroxyl groups were replaced by fluorine atoms with a specific stereochemistry. The synthetic sequence used is shown in Scheme 30.

The results obtained suggest that Glut I transmembrane protein distinguishes $\mathrm{D}$-glucose from its $\mathrm{D}$-altrose analogue recognizing the stereogenicity of the $\mathrm{C}-\mathrm{F}$ bond. Furthermore, for the D-glucose analogue, $\alpha$ - and $\beta$ - anomers are clearly distinguished by the transmembrane protein in favor of the $\alpha$ anomer, similar to D-glucose itself. 


\section{Journal Name}

\section{ARTICLE}

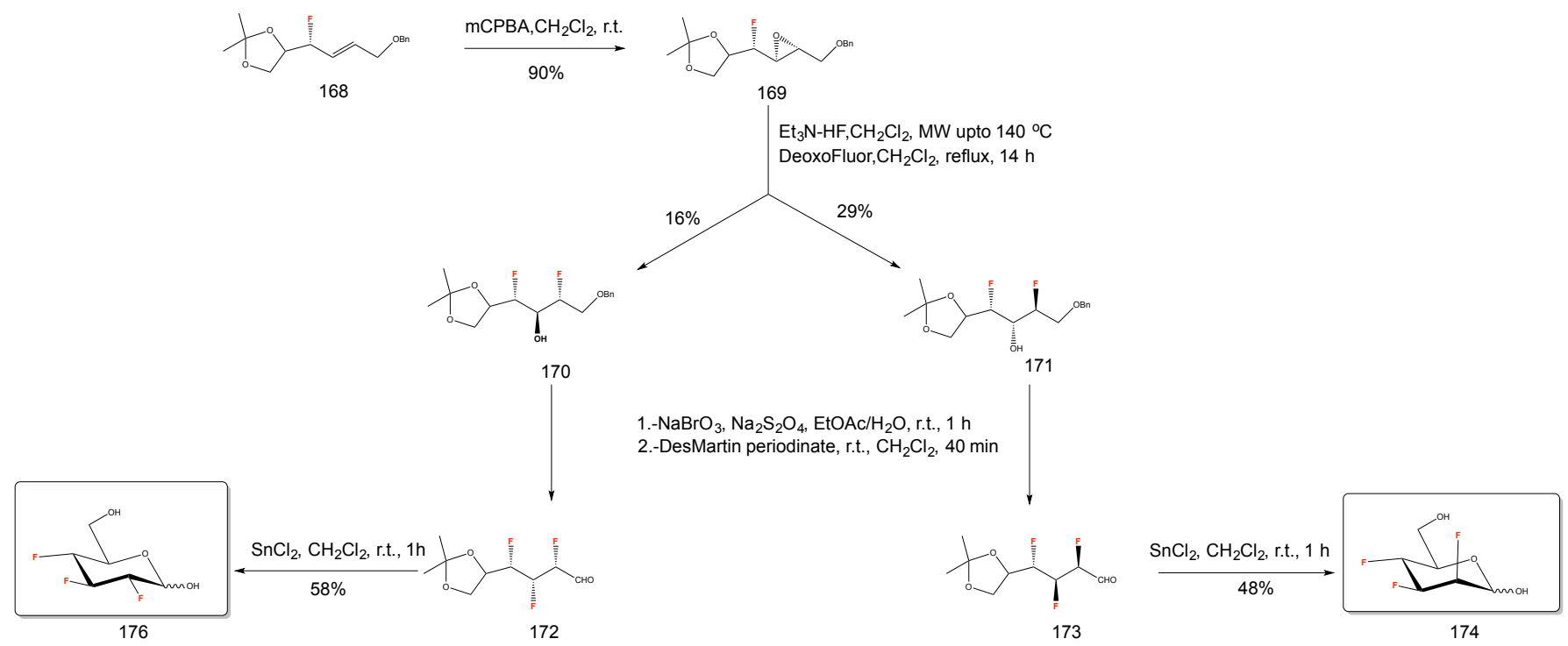

Scheme 30. Synthesis of hexose derived from D-glucose and D-altrose, where the secondary hydroxyl groups were replaced by fluorine atoms with a specific stereochemistry

The synthesis started from epoxidation of protected aldehyde 168 to afford 169 (Scheme 30). Nucleophilic ringopening of epoxide 169 by $\mathrm{Et}_{3} \mathrm{~N}-3 \mathrm{HF}$ yields diastereoisomeric compounds 170 and 171, which by further fluorination and ulterior reduction to the hemiacetals afford compounds $\mathbf{1 7 6}$ and 174.

In another report, the same authors [62] developed the synthesis of a trifluoroglucose 185 in a multistep reaction sequence starting from 2-butyne-1,4-diol 177, according to Scheme 31.

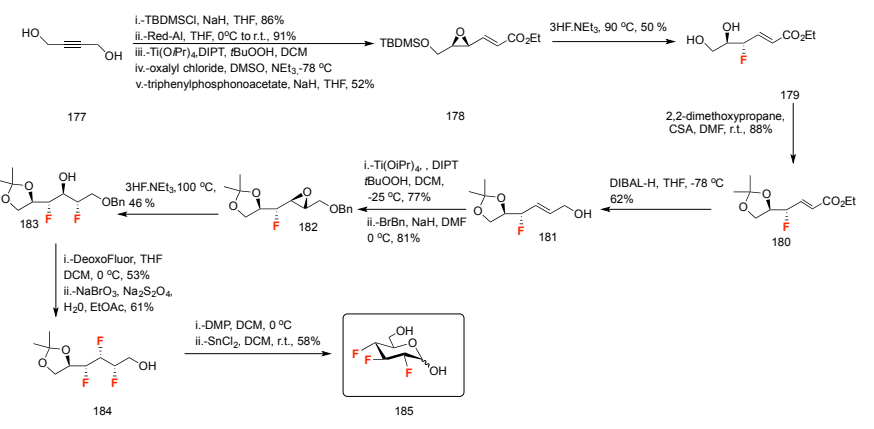

Scheme 31. Reaction sequence for the synthesis of $\mathbf{1 8 5}$

After a protection/reduction/epoxidation/ and oxidation sequence, compound $\mathbf{1 7 8}$ is obtained from 2-butyne-1,4-diol
177. Fluorination of $\mathbf{1 7 8}$ with $3 \mathrm{HF}_{\mathrm{NEt}}$ affords compound $\mathbf{1 7 9 .}$ Diol protection (180) followed by carboxylate reduction (compound 181), and ulterior epoxidation afforded 182 (Scheme 31). Epoxide ring-opening by $3 \mathrm{HF}^{\mathrm{N}} \mathrm{NEt}_{3}$. gives compound 183. Fluorination of $\mathbf{1 8 3}$ by DeoxoFluor, and ulterior reduction yields compound $\mathbf{1 8 4}$ which is converted to the hemiacetal form $\mathbf{1 8 5}$. The overall yield of this reaction is quite low $(0.4 \%$, starting from 177$)$.

Denavit, Giguère and colleagues have very recently accomplished an improved synthesis of 2,3,4-trifluorinated hexopyranoses.[65] The preparation of 2,3,4-trideoxy-2,3,4trifluoroglucopyranose analog 185 depicted in Scheme 32a.

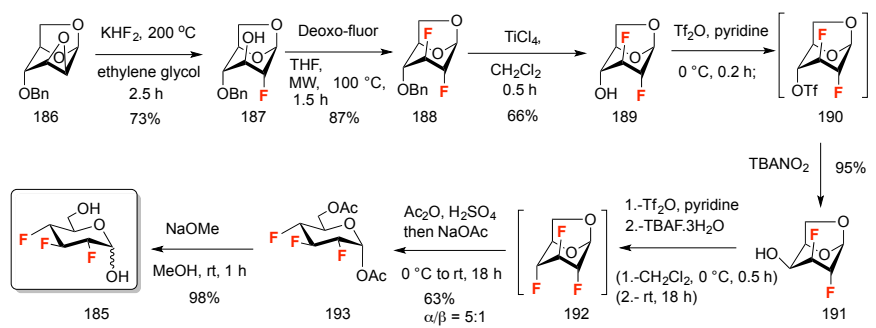

Scheme 32a. Stereoselective synthesis of 2,3,4-trideoxy-2,3,4-trifluoroglucopyranose 185

Compound 186 [67] was subjected to nucleophilic fluorination to yield compound $\mathbf{1 8 7}$ in $\mathbf{7 3 \%}$ yield. Treatment of 
187 with Deoxo-Fluor afforded 2,3-dideoxy-difluoroglucose 188 with complete retention of configuration (2,3-trans relationship). Benzyl deprotection resulted in compound $\mathbf{1 8 9}$ in $66 \%$ yield (Scheme 32).[65] Triflate activation of the free hydroxyl group afforded intermediate 190. Intermediate 190 was subjected to a Lattrell-Dax epimerization allowing the formation of the 1,6-anhydrogalactopyranose derivative 191. Nucleophilic fluorination at C-4 employing TBAF, via a triflate derivative and subsequent acetolysis afforded 2,3-trans-3,4trans-2,3,4-trideoxy-2,3,4-trifluoropyranose 193 from acetylation on intermediate 192. Standard deprotection under basic conditions gave the glucose derivative $\mathbf{1 8 5}$. The synthesis by O'Hagan (vide supra, Scheme 30) has been accomplished in 15 steps in $0.4 \%$ global yield [62] (starting from butynediol 137) whereas the current protocol required a 9-step sequence from epoxide 186 in 25\% overall yield. The authors [65] also completed the syntheses of 2,3,4-trideoxy<2-203k4 trifluoromannopyranose 194 and DO2;3,4-4FideoxpDo2,3,4] trifluorotalopyranose 195 (Figure 5).
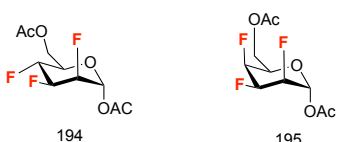

Figure 5. Structures of of 2,3,4-trideoxy-2,3,4-trifluoromannopyranose 194 and 2,3,4trideoxy-2,3,4-trifluorotalopyranose 195 synthesized by Denavit, Giguére and colleagues [65]

Compounds 194 and 195 were synthesized from levoglucosan as starting material (Scheme 32b). The synthetic sequence follows similar sequence that that shown in Scheme $32 \mathrm{a}$.

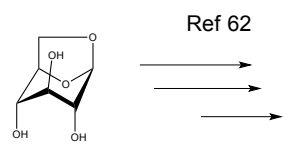

levoglucosan
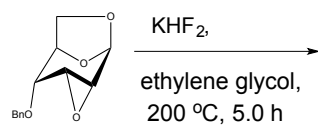
$200^{\circ} \mathrm{C}, 5.0 \mathrm{~h}$

$65 \%$

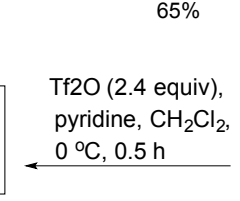
$80^{\circ} \mathrm{C}, 48 \mathrm{~h}$
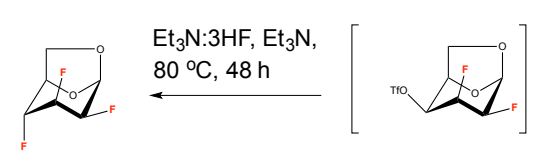

$\mathrm{Ac}_{2} \mathrm{O}, \mathrm{H}_{2} \mathrm{SO}_{4}, 0^{\circ} \mathrm{C}$ to rt, $16 \mathrm{~h}$,

then $\mathrm{NaOAc}, 0^{\circ} \mathrm{C}$ to $\mathrm{rt}, 0.3 \mathrm{~h}$,

$71 \%$ over 3 steps, $\alpha / \beta=10: 1$;

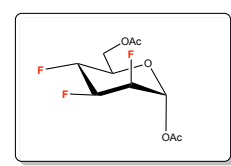

194
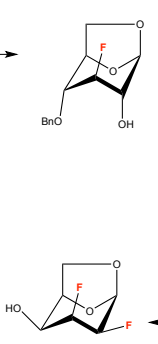

$\mathrm{TBANO}_{2}$

$\mathrm{CH}_{3} \mathrm{CN}$,

microwave irradiation, $100{ }^{\circ} \mathrm{C}, 3 \mathrm{~h}, 91 \%$

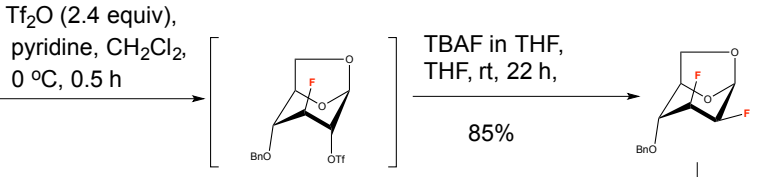

$\mathrm{TiCl}_{4}$ (2.0 equiv), $\mathrm{CH}_{2} \mathrm{Cl}_{2}$, $0{ }^{\circ} \mathrm{C}, 0.8 \mathrm{~h}, 88 \%$

$\mathrm{Tf}_{2} \mathrm{O}$ (2.4 equiv), pyridine, $\mathrm{CH}_{2} \mathrm{Cl}_{2}$, $0{ }^{\circ} \mathrm{C}, 0.5 \mathrm{~h}$

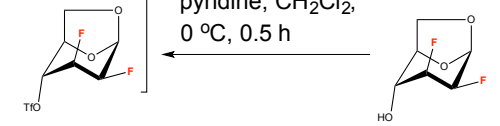

DAST, $\mathrm{CH}_{2} \mathrm{Cl}_{2}$ microwave irradiation, $100^{\circ} \mathrm{C}, 1 \mathrm{~h}$
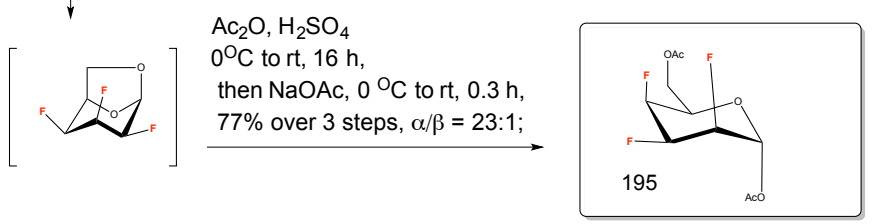

Scheme 32b. Proposed synthesis of 194 and 195 from levoglucosan

Interestingly, the authors [65] managed to synthesize a 2,3-cis, 3,4-cis trifluorinated product 199 in a rapid way, according to Scheme 33.

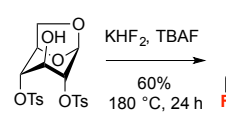

196

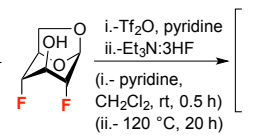

197

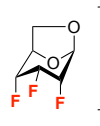

198

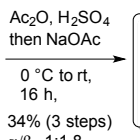

$34 \%(3$ steps $)$
$\alpha / \beta=1: 1.8$

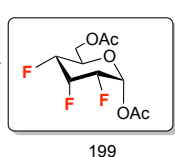

Scheme 33. Rapid synthesis of 2,3,4-trideoxy-2,3,4-trifluoroallopyranose 199

Starting from bis-tosylate 196 (readily accessible from levoglucosan in multigram scale) under treatment with $\mathrm{KHF}_{2}$ and TBAF. $3 \mathrm{H}_{2} \mathrm{O}$ at $180{ }^{\circ} \mathrm{C}$ for $24 \mathrm{~h}$ led to the formation of $1,6-$ anhydro-2,4-dideoxy-2,4-difluoroglucopyranose 197 in $60 \%$ yield. This step permitted the incorporation of two fluorine atoms placed 1,3-syn on the pyranose ring. Compound 197 was activated as triflate and treated with $\mathrm{Et}_{3} \mathrm{~N} .3 \mathrm{HF}$ leading to the formation of diasteroisomer 198 (inversion of configuration at C-3). Acetolysis yielded the fluorinated 199.[65]

\section{3.-Synthesis of tetradeoxy-tetrafluorinated and polyfluorinated saccharides}

In 1998, DiMagno and coworkers [68] synthesized the 1hydroxy-5-hydroxymethyl-2,2,3,3,4,4-hexafluorooxane $\quad 200$ (Figure 6), which was considered an analog of glucose, with enhanced "polar hydrophobicity". DiMagno's hypotheses stated that by decreasing the polarizability of a given active compound, without changing its charge distribution and geometry, an enhanced-binding analogue would be obtained. The substitution of a $-\mathrm{CHOH}-$ group by a $-\mathrm{CF}_{2}-$ would fulfil this requirement, as $\mathrm{C}-\mathrm{F}$ bond is highly polar but its polarization is of very little significance. Moreover, the hydrophobic desolvation of the $-\mathrm{CF}_{2}-$ would positively contribute to the whole process. The authors [68] could demonstrate a 10-fold increase in the membrane transport of this hexafluoro-glucose mimetic, as a 
consequence of an enhanced binding with the transporter protein.

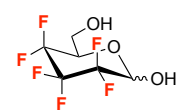

200

Figure 6. 1-Hydroxy-5-hydroxymethyl-2,2,3,3,4,4-hexafluorooxane 200

The replacement of multiple $-\mathrm{CHOH}-$ units present in carbohydrates by $-\mathrm{CF}_{2}-$ and $-\mathrm{CHF}$-groups has also been addressed by Vincent and coworkers [69] as a strategy to get carbohydrate mimetics with enhanced affinity for target proteins. The authors considered that by decreasing the pronounced hydrophilicity of carbohydrates, an increase in the affinity of protein-carbohydrate interactions would take place.

In fact, it was shown that tetrafluorination of C-2 and C-3 positions of a galactose-mimetic [69] resulted in a significant enhancement of the binding to the UDP-galactopyranose mutase, a relevant enzyme involved in the biosynthesis of the mycobacterial cell wall (Scheme 34).

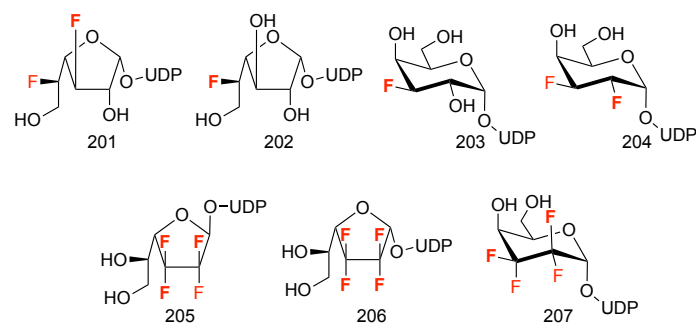

Scheme 34. Tetrafluorination of furanose and galactose mimetics towards the inhibition of UDP-galactopyranose mutase 207

The syntheses of the tetrafluoro furanoses (Scheme 35) were performed through a de novo strategy by orthogonal protection of the hydroxyl groups of the diol (208), followed by a metal-halogen exchange reaction (209). After phosphorylation and deprotection, the desired tetrafluorinated nucleotide sugars were obtained (compounds 205-207, Scheme 35).

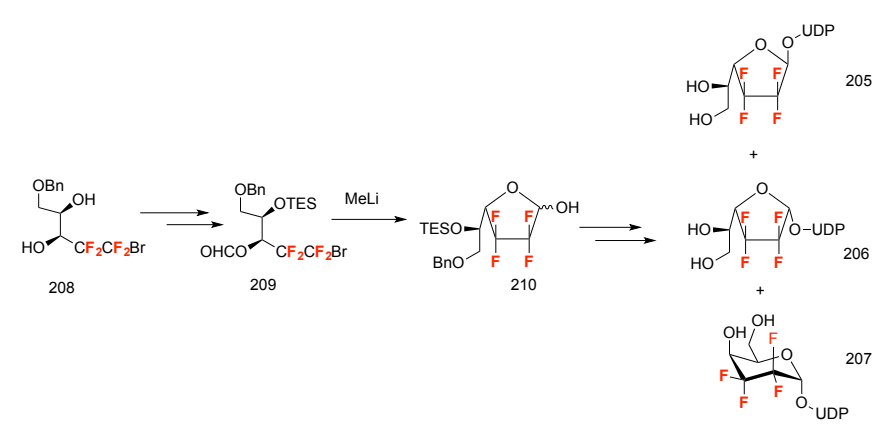

Scheme 35. Synthesis of tetrafluorinated nucleotide sugars 205-207

In a more recent report, Linclau and co-workers $[70,71]$ achieved the synthesis of tetrafluorinated monosaccharides by

a fluorinated de novo strategy. The authors [70] described the syntheses of four possible dideoxy-tetrafluopinated pypartose derivatives and for one of these, the synthesis in the furanose form (i.e.: the improved synthetic approach for 2,3-dideoxy2,2,3,3-tetrafluoro-D-threo-hexopyranose 211, 2,3-dideoxy2,2,3,3,-tetrafluoro-D-threo-hexofuranose 212, 2,3-dideoxy2,2,3,3,-tetrafluoro-D-erythro-hexopyranose $\mathbf{2 1 3}$, novel 3,4dideoxy-3,3,4,4-tetrafluoro-D-threo-hexopyranose 214 and 3,3,4,4-tetrafluoro-D-erythro-hexopyranose 215) (Figure 7).

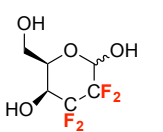

211

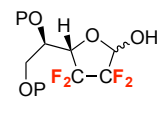

212

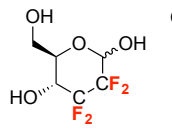

213

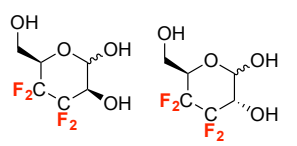

214

215
Figure 7. Structures of tetrafluorinated monosaccharides 211-215

The synthesis of $\mathbf{2 1 1}$ has been accomplished by a de novo approach according to Scheme 36.

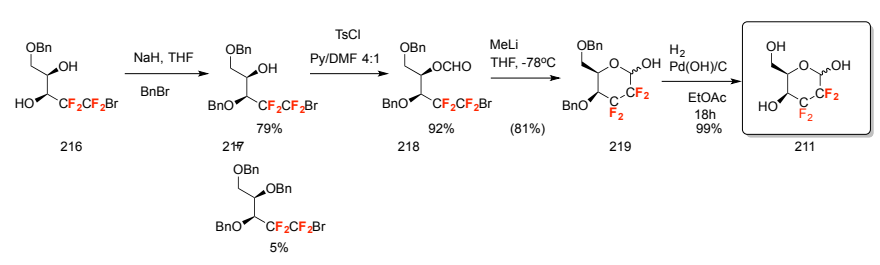

Scheme 36. Synthesis of 2,3-dideoxy-2,2,3,3-tetrafluoro-D-threo-hexopyranose $\mathbf{2 1 1}$

Selective benzylation from precursor $\mathbf{2 1 6}$ was achieved on account of the acidity of the hydroxyl group next to the perfluoroalkyl moiety, rendering $\mathbf{2 1 7}$ in $\mathbf{8 9 \%}$ yield. Formylation of the remaining hydroxyl group in $\mathbf{2 1 7}$ was accomplished by activation with DMF and tosyl chloride in pyridine as solvent affording product $\mathbf{2 1 8}$ in $92 \%$ yield. Through MeLi [72] and ulterior deprotection of 219, 211 was obtained in $60 \%$ overall yield, starting from 216.[70]

The glucopyranose 223, was synthesized in a similar fashion, starting from 220 , according to Scheme 37 , in $42 \%$ yield.

$$
\text { Scheme 37. Synthesis of 2,3-dideoxy-2,2,3,3,-tetrafluoro-D-erythro-hexopyranose } 223
$$

The syntheses of pyranose rings 214 and 215 were performed according to Scheme 38. Enantiopure monoprotected diol 224 [73] was subjected to DDQ-mediated oxidation under anhydrous conditions, giving $\mathbf{2 2 5}$ as a mixture of diastereomers. Bromine-lithium exchange followed by cinnamaldehyde addition afforded $\mathbf{2 2 6}$ as a mixture of four diastereomers. The mixture was subjected to acetal deprotection leading to a mixture of $\mathbf{2 2 7}$ (syn and anti-isomers) in $71 \%$ combined yield. Lastly, ozonolysis afforded a mixture of carbohydrate derivatives 214 and 215 (Scheme 38). [70] 


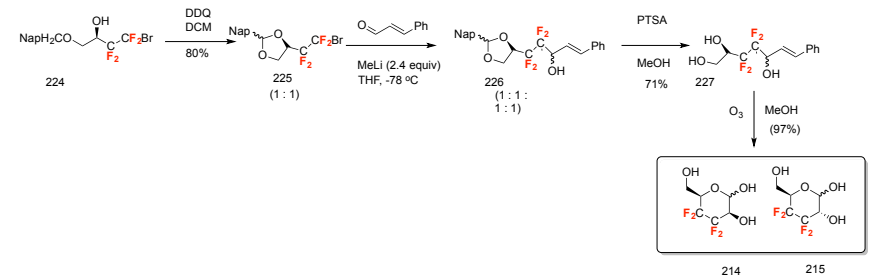

Scheme 38. Synthesis of novel 3,4-dideoxy-3,3,4,4-tetrafluoro-D-threo-hexopyranose 214 and 3,3,4,4-tetrafluoro-D-erythro-hexopyranose 215

The synthesis of furanose ring $\mathbf{2 1 2}$ (Figure 7) has been described in Scheme 35 (210, R = TES), according to the protocol of Vincent. However, Linclau and colleagues [70] optimized the synthetic procedure, according to Scheme 39.

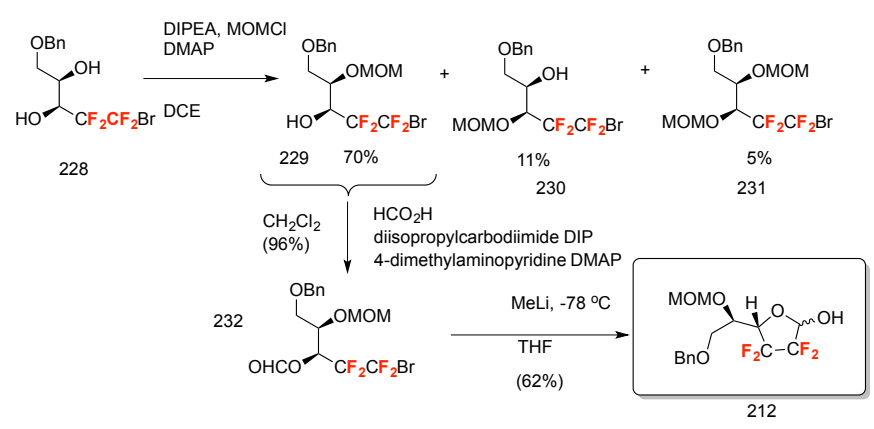

Scheme 39. Improved synthesis of 2,3-dideoxy-2,2,3,3-tetrafluoro-D-threohexofuranose 212

Reaction of diol 228 with $\mathrm{MOMCl}$ led to the desired monoprotected $\mathbf{2 2 9}$, in $70 \%$ yield. Formylation of the remaining alcohol group (in compound 229) and anionic cyclization, led to furanose derivative $\mathbf{2 1 2}$ in $\mathbf{4 1 \%}$ yield, starting from $\mathbf{2 2 8}$ (Scheme 39).[70]

\section{4.-CONCLUSIONS}

Presenting the array of strategies for accomplishing stereoselective fluorinations at the different positions of the sugar moiety reveals the powerful influence that fluorine substitution exerts on the sugar scaffold when designing carbohydrate mimics and inhibitors, and the dominant role of fluorine on the structure-activity relationship of substituted carbohydrates. Fluorine substitution can have profound effects on conformational equilibria and lock the structures into specific conformers, thus altering biological activity in beneficial ways. Also, considerations related to the increase in hydrophobicity, polarity, low polarizability, and hydrogenacceptor- bonding capability resulting from fluorine substitution transforms the structure-activity relationship of carbohydrates.

A less explored area regarding fluorination methods of carbohydrates which needs further studies is radical fluorination chemistry, which could open up new possibilities in terms of stereo- and regioselectivity in fluorine substitution. Also, photocatalytic fluorination reactions have not been fully explored in carbohydrate chemistry.

\section{Conflicts of interest}

There are no conflicts to declare.

View Article Online DOI: 10.1039/C9OB00405J

\section{Acknowledgements}

MLU and AP are research members of Conicet (Consejo Nacional de Investigaciones Científicas y Técnicas). Thanks are given to Universidad de Buenos Aires for financial support.

\section{references}

1 L. L. Lairson, B. Henrissat, G. J. Davies and S. G. Withers, Annu. Rev. Biochem., 2008, 77, 521-55.

2 P. Bojarová and V. Křen, Trends in Biotechnology, 2009, 27, 199-209.

3 H. Ghazarian, B. Idoni and S. B. Oppenheimer, Acta Histochem., 2011 113, 236-247.

4 M. Kunigami and S. Hara, Carbohydr. Res., 2015, 417, 78-80.

5 M. Sharma, R. J. Bernacki, and W. Korytnyk. "Fluorinated Analogs of Cell-Surface Carbohydrates as Potential Chemotherapeutic Agents", ACS Symposium Series, Vol. 374, Chapter 11. DOI: 10.1021/bk-1988-0374.ch011.

6 D. L. Zechel and S. G. Withers, Acc. Chem. Res., 2000, 33, 1118.

7 J. C. Errey, M. C. Mann, S. A. Fairhurst, L. Hill, M. R. McNeil, J. H. Naismith, J. M. Percy, C. Whitfield and R. A. Field, Org. Biomol. Chem., 2009, 7, 1009-1016.

8 A. J. Boydell, V. Vinader and B. Linclau, Angew. Chem., 2004, 116, $5795-5797$.

9 T. Oberbillig, C. Mersch, S. Wagnerb and A. Hoffmann-Röder, Chem. Commun., 2012, 48, 1487-1489.

10 G. T. Giuffredi, L. E. Jennings, B. Bernet and V. Gouverneur, J. Fluorine Chem., 2011, 132, 772-778.

11 H. J. Schneider, Chem. Sci., 2012, 3, 1381-1394.

12 J. Graton, Z. Wang, A. M. Brossard, D. G. Monteiro, J.-Y. Le Questel and B. Linclau, Angew. Chemie Int. Ed., 2012, 51, 6176-6180.

13 L. Quiquempoix, E. Bogdan, N. J. Wells, J.-Y. Le Questel, J. Graton and B. Linclau, Molecules, 2017, 22, 518, 1-14.

14 B. Bernet and A. Vasella, Helv. Chim. Acta, 2007, 90, 18741883.

15 H. Takemura, R. Ueda and T. Iwanaga, J. Fluorine Chem., 2009, 130, 684-688.

16 H. Takemura, M. Kaneko, K. Sako and T. Iwanaga, New J. Chem., 2009, 33, 2004-2006.

17 P. A. Champagne, J. Desroches and J.-F. Paquin, Synthesis, 2015, 47, 306-322.

18 G. T. Giuffredi, V. Gouverneur and B. Bernet, Angew. Chemie Int. Ed., 2013, 52, 10524-10528.

19 (a) A. Baumann, S. Marchner, M. Daum and A. HoffmannRoder, Eur. J. Org. Chem., 2018, 3803-3815. (b) T. Diercks, A. S. Infantino, L. Unione, J. Jimenez-Barbero, S. Oscarson and H.J. Gabius, Chem. Eur. J., 2018, 24, 15761-15765.

20 S. André, F. J. Cañada, T. C. Shiao, L. Largartera, T. Diercks, M. Bergeron-Brlek, Khouzaima el Biari, A. Papadopoulos, J. P. Ribeiro, M. Touaibia, D. Solís, M. Menéndez, J. JiménezBarbero, R. Roy and H.-J. Gabius, Eur. J. Org. Chem., 2012, 4354-4364.

21 T. Diercks, J. P. Ribeiro, F. J. Cañada, S. André, J. JiménezBarbero and H.-J. Gabius, Chem. Eur. J., 2009, 15, 5666- 5668.

22 (a) A. Ardáa and J. Jiménez-Barbero, Chem. Comm., 2018, 54, 4761-4769. (b) E. Matei, S. André, A. Glinschert, A. Simona Infantino, S. Oscarson, H.-J. Gabius and A. M. Gronenborn, Chem. Eur. J., 2013, 19, 5364-5374. 
23 M. Braitsch, H. Kählig, G. Kontaxis, M. Fischer, T. Kawada, R. Konrat and W. Schmid, Beilstein J. Org. Chem., 2012, 8, 448455.

24 Y. Yuan, D. W. Bleile, X. Wen, D. A. R. Sanders, K. Itoh, H.-W. Liu and B. M. Pinto, J. Am. Chem. Soc., 2008, 130, 3157-3168.

25 G. R. Morais, R. A. Falconer and I. Santos, Eur. J. Org. Chem., 2013, 1401-1414.

26 P. E. Edem, E. J. L. Steen, A. Kjær and M. M. Herth: Chapter 2: "Fluorine-18 Radiolabeling Strategies- Advantages and Disadvantages of Currently Applied Labeling Methods" in "Late-stage fluorination of bioactive compounds and biological relevant substrates". Ed. Al Postigo, Elsevier, 2018, ISBN: 978-0-12-812958-6.

27 (a) Y. Cheng, A.-L. Guo and D.-S. Guo, Curr. Org. Chem., 2010, 14, 977-999. (b) R. Miethchen, J. Fluorine Chem., 2004, 125 895-911. (c) B. Novo and G. Resnati: Stereocontrolled synthesis of fluorinated carbohydrates, John Wiley \& Sons, Chichester, UK. Ed. Vadim A. Sloshnokov

28 K. Dax, M. Albert, J. Ortner and B. J. Paul, Carbohydr. Res., 2000, 327, $47-86$.

29 M. Hein and R. Miethchen, Advances in Organic Synthesis, 2006, 2, 381-429.

30 E. Leclerc, X. Pannecouke, M. Etheve-Quelquejeu and M. Sollogoub, Chem. Soc. Rev., 2013, 42, 4270-4283.

31 S. G. Withers, D. J. Maclennan and I. P. Stree, Carbohydr. Res., 1986, 154, 127-144.

32 W. Subotkowski, D. Friedrich and F. J. Weiberth, Carbohydr. Res., 2011, 346, 2323-2326.

33 (a) S. Kobayashi, A. Yoneda, T. Fukuhara and S. Hara, Tetrahedron Letters, 2004, 45, 1287-1289. (b) D. Waschke, Y. Lesch, J. Thimm, U. Himmelreich and J. Thiem, Eur. J. Org. Chem., 2012, 948-959.

34 P.A: Champagne, J. Desroches, J.D. Hamel, M. Vandamme and J.-F. Paquin, Chem. Rev., 2000, 327, 9073-9174.

35 (a) X.-Q. Yin and S. W. Schneller, Tetrahedron Lett., 2005, 46, 7535-7538. (b) B. Doboszewski, G. W. Hay and W. A. Szarek, Can. J. Chem., 1987, 65, 412-419.

36 R. Miethchen and G. Kolp, J. Fluorine Chem., 1993, 60, 49-55.

37 (a) S. Stavber and M. Zupan, Adv. Org. Synth., 2006, 2, 213268. (b) P.T. Nyffeler, S.G. Durón, M.D. Burkart, S.P. Vincent and C.-H. Wong, Angew. Chem. Int. Ed., 2005, 44, 192-212. (c) K. Dax, M. Albert, J. Ortner and B.J. Paul, Carbohydr. Res., 2000, 327, 47-86.

38 J.P. Bégué and D. Bonnet-Delpon, Bioorg. \& Med. Chem. of Fluorine, John Wiley \& Sons Inc. Hoboken, 2008.

39 K. Toshima, Carbohydr. Res., 2000, 327, 15-26.

40 (a) M. D. Burkart, Z. Zhang, S.-C. Hung and C.-H. Wong, J. Am. Chem. Soc., 1997, 119, 11743-11746. (b) Q. Zhang and Hungwen Liu, J. Am. Chem. Soc., 2001, 123, 6756-6766.

41 O. Kanie, Carbohydr. Res., 2012, 359, 81-91.

42 S. P. Vincent, M. D. Burkart, C.-Y. Tsai, Z. Zhang and C.-H. Wong, J. Org. Chem., 1999, 64, 5264-5279.

43 H. Dohi, R. P rion, M. Durka, M. Bosco, Y. Rou, F. Moreau, S. Grizot, A. Ducruix, S. Escaich and S. P. Vincent, Chem. Eur. J., 2008, 14, 9530-9539.

44 S. P. Vincent and A. Tikad, Isr. J. Chem., 2015, 55, 392- 397.

45 C. Bucher and R. Gilmour, Angew. Chem. Int. Ed., 2010, 49, 8724-8728.

46 A. Sadurni, G. Kehr, M. Ahlqvist, J. Wernevik, H. Peilot Sjögren, C. Kankkonen, L. Knerr and R. Gilmour, Chem. Eur. J., 2018, 24 2832-2836.

47 N. Santschi and R. Gilmour, Eur. J. Org. Chem., 2015, 69836987.

48 D. Lainé, V. Denavit, and D. Giguère, J. Org. Chem., 2017, 82, 4986-4992.

49 Y. Akiyama, C. Hiramatus, T. Fukuhara and S. Hara, J. Fluorine Chem., 2006, 127, 920-923.
50 N. Yan, Z.-W. Lei, J.-K. Su, W.-L. Liao and X.-G. Hu, Chinese Chem. Lett., 2017, 23, 467-470. DOl: 10.1039/C9OB00405]

51 M. Cerný, Adv. Carbohydr. Chem. Biochem., 2003, 58, 122198.

52 Š. Horník, L. Č. Štastná, P. Cuřínová, J. Sýkora, K. Káňová, R. Hrstka, I. Císařová, M. Dračínský and J. Karban, Beilstein J. Org. Chem., 2016, 12, 750-759.

53 N. A. Petasis and E. I. Bzowej, J. Am. Chem. Soc., 1990, 112, 6392-6394.

54 M. Schalli, M. Thonhofer, A. Wolfsgruber, H. Weber, R. Fischer, R. Saf and A. E. Stütz, Carbohydr. Res., 2016, 436, 1119.

55 A. Burton, P. Wyatt and G.-J. Boons, J. Chem. Soc., Perkin Trans., 1997, 1, 2375-2382.

56 M. C. T. Hartman and J. K. Coward, J. Am. Chem. Soc., 2002, 124, 10036-10053.

57 M. Thonhofer, A. Gonzalez Santana, R. Fischer, A. Torvisco Gomez, R. Saf, M. Schalli, A. E. Stütz and S. G. Withers, Carbohydr. Res., 2016, 420, 6-12.

58 J. D. McCarter and S. G. Withers, J. Am. Chem. Soc., 1996, 118, 241-242.

59 S. J. Williams and S. G. Withers, Carbohydr. Res., 2000, 327, 27-46.

60 Y. Nishida and J. Thiem, Carbohydr. Res., 1994, 263, 295-301.

61 M. Bols and I. Lundt, Acta Chem. Sacand., 1990, 44, 252-256.

62 M.J. Corr and D. O'Hagan, J. Fluorine Chem., 2013, 155, 72-77.

63 Y. Akiyama, T. Fukuhara and S. Hara, Synlett, 2003, 1530-1532.

64 L. Mtashobya, L. Quiquempoix and B. Linclau, J. Fluorine Chem., 2015, 171, 92-96.

65 V. Denavit, D. Lainé, J. St-Gelais, P. A. Johnson and D. Giguère, Nature Commun., 2018, 9, 4721.

66 D. O'Hagan, Chem. Commun., 2010, 46, 5434-5436.

67 T. Trinka, M. Cerny, Collect. Czech. Chem. Comm., 1971, 36, 2216-2225.

68 H. Woo Kim, P. Rossi, R. K. Shoemaker and S. G. DiMagno, J. Am. Chem. Soc., 1998, 120, 9082-9083

69 I. N’Go, S. Golten, A. Ardá, J. Cañada, J. Jiménez-Barbero, B. Linclau and S. P. Vincent, Chem. Eur. J., 2014, 20, 106-112

70 S. Golten, C. Q. Fontenelle, R. S. Timofte, L. Bailac, M. Light, M. Sebban, H. Oulyadi, and B. Linclau, J. Org. Chem., 2016, 81, 4434-4453.

71 A. Ioannou, E. Cini, R. S. Timofte, S. L. Flitsch, N. J. Turner and B. Linclau, Chem. Commun., 2011, 47, 11228-11230.

72 T. Konno, T. Hoshino, T. Kida, S. Takano, T. Ishihara, J. Fluorine Chem., 2013, 152, 106-113

73 B. Linclau, A. J. Boydell, R. S. Timofte, K. J. Brown, V. Vinader, A. C. Weymouth-Wilson, Org. Biomol. Chem., 2009, 7, 803814. 